\title{
Effectiveness of Einsteinium Nanoparticles in Optothermal Human Cancer Cells, Tissues and Tumors Treatment under Synchrotron Radiation
}

\author{
Alireza Heidari ${ }^{1,2,}$, Katrina Schmitt ${ }^{1}$, Maria Henderson ${ }^{1}$ and Elizabeth Besana ${ }^{1}$ \\ ${ }^{1}$ Faculty of Chemistry, California South University, 14731 Comet St. Irvine, CA 92604, USA \\ ${ }^{2}$ American International Standards Institute, Irvine, CA 3800, USA
}

\begin{abstract}
In the current study, thermoplasmonic characteristics of Einsteinium nanoparticles with spherical, core-shell and rod shapes are investigated. In order to investigate these characteristics, interaction of synchrotron radiation emission as a function of the beam energy and Einsteinium nanoparticles were simulated using 3D finite element method. Firstly, absorption and extinction cross sections were calculated. Then, increases in temperature due to synchrotron radiation emission as a function of the beam energy absorption were calculated in Einsteinium nanoparticles by solving heat equation. The obtained results show that Einsteinium nanorods are more appropriate option for using in optothermal human cancer cells, tissues and tumors treatment method.
\end{abstract}
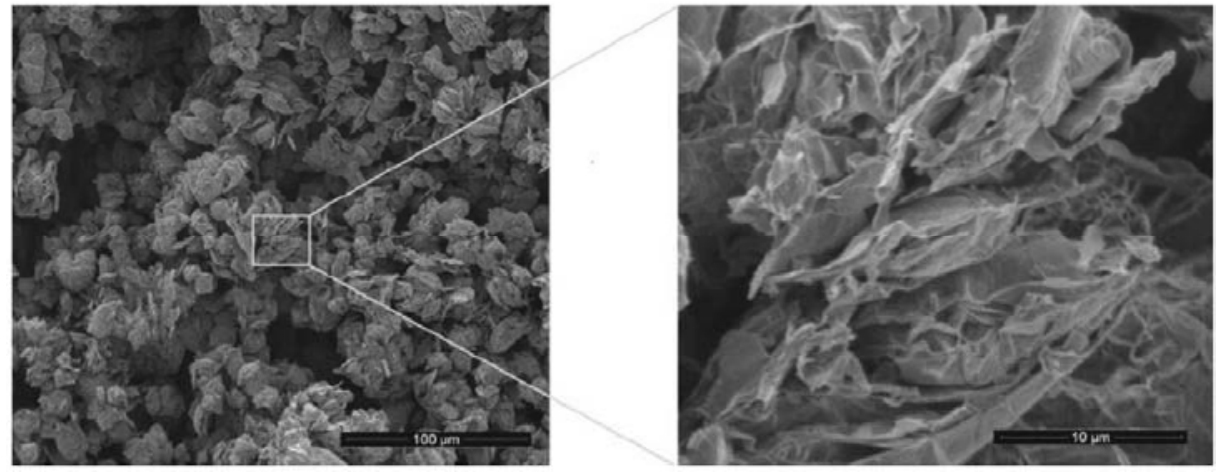

Scanning Electron Microscope (SEM) image of Einsteinium nanoparticles with 50000x zoom.

Keywords: Einsteinium Nanoparticles, Scanning Electron Microscope (SEM), 3D Finite Element Method (FEM), Heat Transfer Equation, Optothermal, Heat Distribution, Thermoplasmonic, Einsteinium Nanorods, Human Cancer Cells, Tissues and Tumors Treatment, Simulation, Synchrotron Radiation, Emission, Function, Beam Energy.

\section{INTRODUCTION}

In recent decade, metallic nanoparticles have been widely interested due to their interesting optical characteristics [1-8]. Resonances of surface Plasmon in these nanoparticles lead to increase in synchrotron radiation emission as a function of the beam energy scattering and absorption in related frequency [9, 10]. Synchrotron radiation emission as a function of the beam energy absorption and induced produced heat in nanoparticles has been considered as a side effect in plasmonic applications for a long time [11-15]. Recently, scientists find that thermoplasmonic characteristic can be used for various optothermal applications in cancer, nanoflows and photonic [16-22]. In optothermal human cancer cells, tissues and tumors

*Address correspondence to this author at the American International Standards Institute, Irvine, CA 3800, USA; Tel/Fax: +1-775-410-4974; E-mail: Scholar.Researcher.Scientist@gmail.com, Alireza.Heidari@calsu.us, Central@aisi-usa.org treatment, the descendent laser light stimulate resonance of surface Plasmon of metallic nanoparticles and as a result of this process, the absorbed energy of descendent light converse to heat in nanoparticles [2325]. The produced heat devastates tumor tissue adjacent to nanoparticles without any hurt to sound tissues [26, 27]. Regarding the simplicity of ligands connection to Einsteinium nanoparticles for targeting cancer cells, these nanoparticles are more appropriate to use in optothermal human cancer cells, tissues and tumors treatment [28-74]. In the current paper, thermoplasmonic characteristics of spherical, coreshell and rod Einsteinium nanoparticles are investigated.

\section{HEAT GENERATION IN SYNCHROTRON RADIATION EMISSION AS A FUNCTION OF THE BEAM ENERGY-EINSTEINIUM NANOPARTICLES INTERACTION}

When Einsteinium nanoparticles are subjected to descendent light, a part of light scattered (emission 
process) and the other part absorbed (non-emission process). The amount of energy dissipation in nonemission process mainly depends on material and volume of nanoparticles and it can be identified by absorption cross section. At the other hand, emission process which its characteristics are depend on volume, shape and surface characteristics of nanoparticles explains by scattering cross section. Sum of absorption and scattering processes which lead to light dissipation is called extinction cross section [75123].

Einsteinium nanoparticles absorb energy of descendent light and generate some heat in the particle. The generated heat transferred to the surrounding environment and leads to increase in temperature of adjacent points to nanoparticles. Heat variations can be obtained by heat transfer equation [124-202].

\section{SIMULATION}

To calculate the generated heat in Einsteinium nanoparticles, COMSOL software which works by Finite Element Method (FEM) was used. All simulations were made in 3D. Firstly, absorption and scattering cross section areas were calculated by optical module of software. Then, using heat module, temperature variations of nanoparticles and its surrounding environment were calculated by data from optical module [203-283]. In all cases, Einsteinium nanoparticles are presented in water environment with dispersion coefficient of 1.84 and are subjected to flat wave emission with linear polarization. Intensity of descendent light is $1 \mathrm{~mW} / \mu \mathrm{m}^{2}$. Dielectric constant of Einsteinium is dependent on particle size [284-387].

Firstly, calculations were made for Einsteinium nanospheres with radius of $5,10,15,20,25,30,35$, 40, 45 and 50 nanometers. The results show that by increase in nanoparticles size, extinction cross section area increases and maximum wavelength slightly shifts toward longer wavelengths. The maximum increase in temperature of nanospheres in surface Plasmon frequency is shown in Figure 1.

According to the graph, it can be seen that the generated heat is increased by increase in nanoparticles size. For $100(\mathrm{~nm})$ nanoparticles (sphere with 50 ( $\mathrm{nm})$ radius), the maximum increase in temperature is $83(\mathrm{~K})$. When nanoparticles size reaches to $150(\mathrm{~nm})$, increase in temperature is increased in spite of increase in extinction coefficient. In order to find the reason of this fact, ratio of absorption to extinction for various nanospheres in Plasmon frequency is shown in Figure 2.

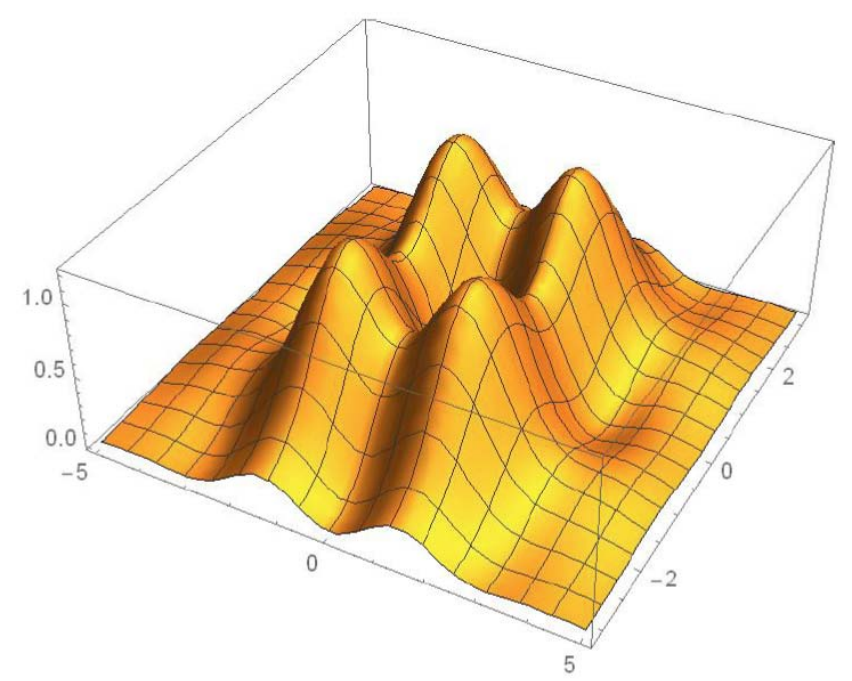

Figure 1: Maximum increase in temperature for Einsteinium nanospheres.

Figure 2 shows that increasing the size of nanospheres leads to decrease in ratio of light absorption to total energy of descendent light so that for $150(\mathrm{~nm})$ nanosphere, scattering is larger than absorption. It seems that although increase in nanoparticles size leads to more dissipation of descendent light, the dissipation is in the form of scattering and hence, it cannot be effective on heat generation.

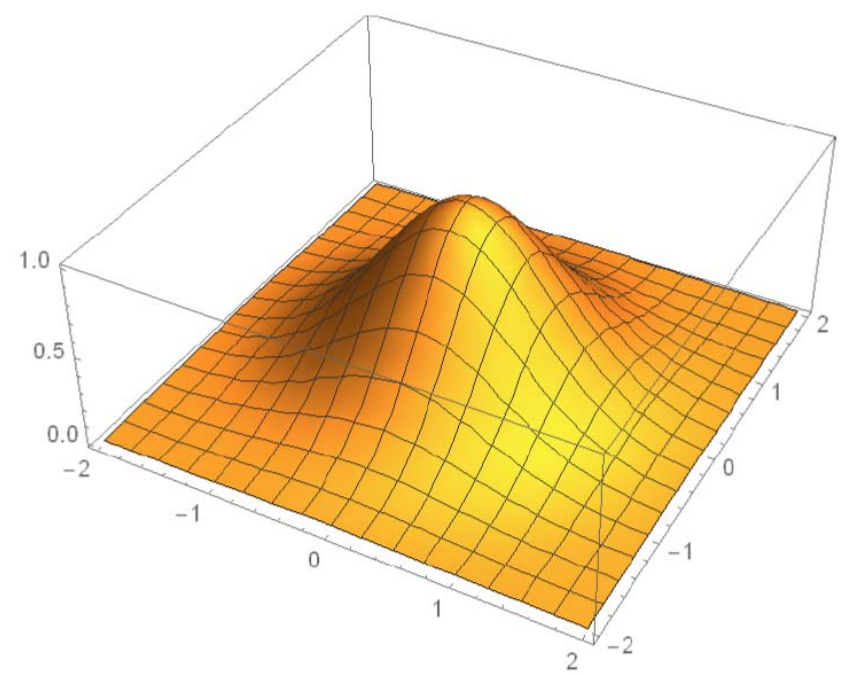

Figure 2: Variations of absorption to extinction ratio and scattering to extinction ratio for Einsteinium nanospheres with various radiuses.

Heat distribution (Figure 3) shows that temperature is uniformly distributed throughout the nanoparticles which are due to high thermal conductivity of Einsteinium. 


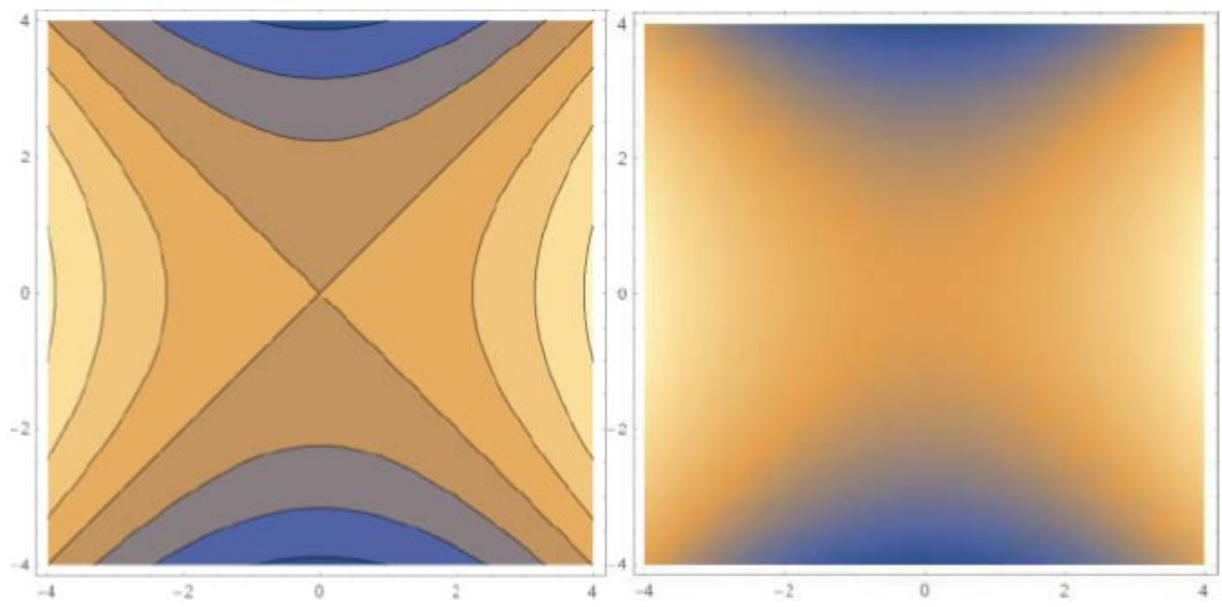

Figure 3: Maximum increase in temperature for spherical nanoparticles with radius of 45 (nm) at Plasmon wavelength of 685 $(\mathrm{nm})$.

In this section, core-shell structure of Einsteinium and silica is chosen. The core of a nanosphere with 45 $(\mathrm{nm})$ radius and silica layer thickness of $5,10,15,20$, $25,30,35,40,45$ and 50 nanometers are considered. The results show that increase in silica thickness leads to increase in extinction coefficient and shift in Plasmon wavelength of nanoparticles, to some extent.

According to Figure 4, silica shell causes to considerable increase in temperature of Einsteinium nanoparticles but by more increase in silica thickness, its effects are decreased. Heat distribution (Figure 5) shows that temperature is uniformly distributed throughout metallic core as well as silica shell. However, silica temperature is considerably lower than core temperature due to its lower thermal conductivity. In fact, silica layer prohibits heat transfer from metal to

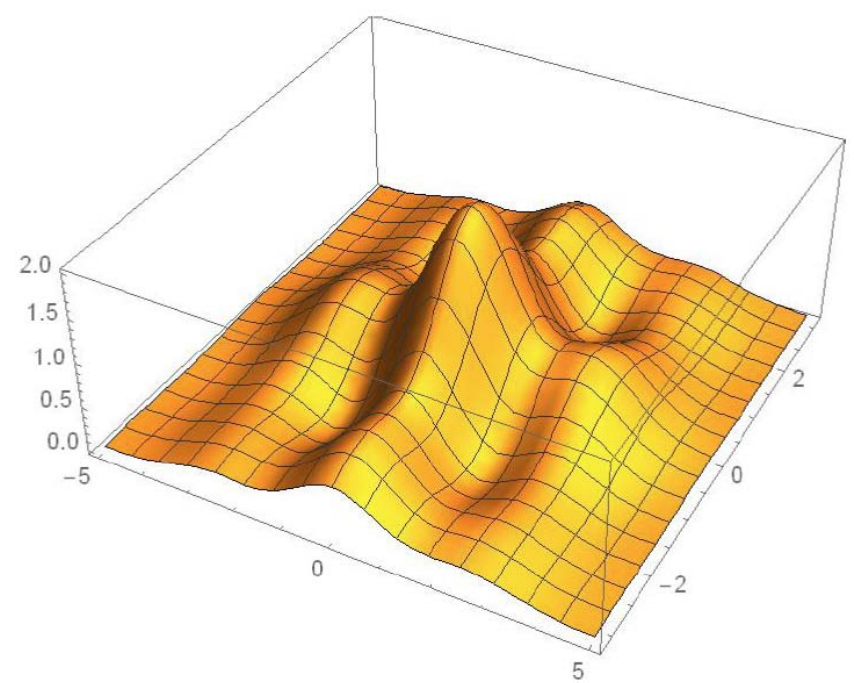

Figure 4: Maximum increase in temperature for core-shell Einsteinium nanospheres with various thicknesses of silica shell. the surrounding aqueous environment due to low thermal conductivity and hence, temperature of nanoparticles has more increase in temperature. Increasing the thickness of silica shell leads to increase in its thermal conductivity and hence, leads to attenuate in increase in nanoparticles temperature.

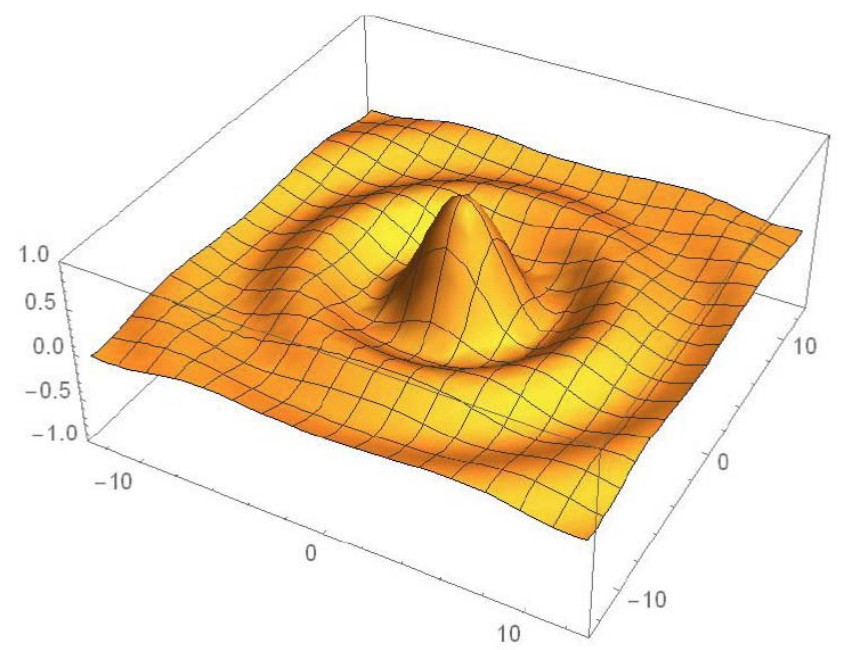

Figure 5: Maximum increase in temperature for core-shell nanoparticles with radius of $45(\mathrm{~nm})$ and silica thickness of 10 $(\mathrm{nm})$ at Plasmon wavelength of $701(\mathrm{~nm})$.

Figure 6 is drawn. This graph shows that variation of nanorod dimension ratio leads to considerable shift in Plasmon wavelength. This fact allows regulating the Plasmon frequency to place in near IR zone. Light absorption by body tissues is lower in this zone of spectrum and hence, nanorods are more appropriate for optothermal human cancer cells, tissues and tumors treatment methods.

Variations of temperature in Einsteinium nanorods with two effective radius and various dimension ratios 

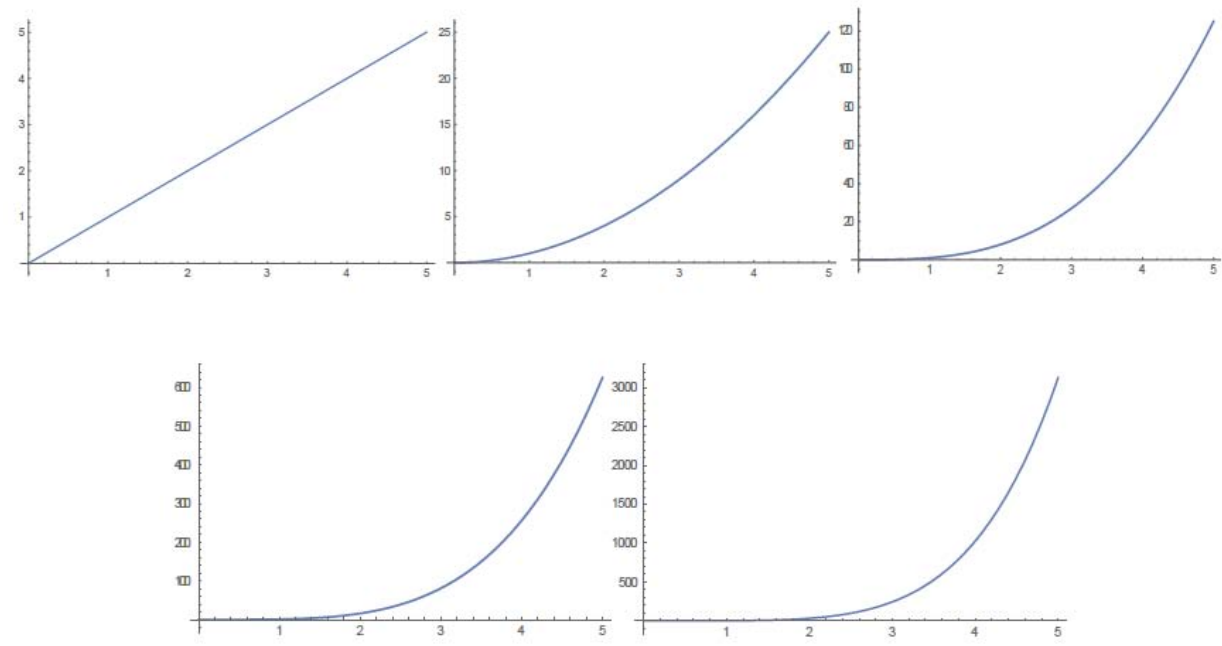

Figure 6: Extinction cross section area for Einsteinium nanorods with effective radius of 45 (nm) and various dimension ratios.

are shown in Figure 7. By increase in length (a) to radius (b) of nanorod, temperature is increased.

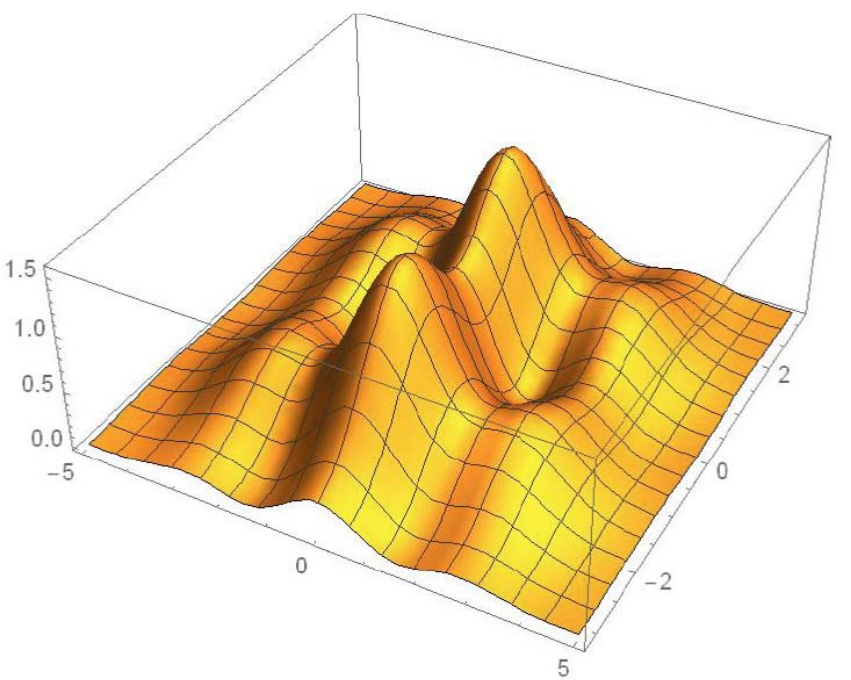

Figure 7: Maximum increase in temperature for nanorods with effective radius of 20 and $45(\mathrm{~nm})$ and various dimension ratios.

\section{CONCLUSION AND SUMMARY}

The calculations showed that in Einsteinium nanoparticles, light absorption in Plasmon frequency causes to increase in temperature of the surrounding environment of nanoparticles. In addition, it showed that adding a thin silica layer around the Einsteinium nanospheres increases their temperatures. Calculations of nanorods showed that due to ability for shifting surface Plasmon frequency toward longer wavelength as well as more increase in temperature, this nanostructure is more appropriate for medical applications such as optothermal human cancer cells, tissues and tumors treatments.

\section{ACKNOWLEDGEMENTS}

Authors are supported by an American International Standards Institute (AISI) Future Fellowship Grant FT12010093734726. We acknowledge Ms. Isabelle Villena for instrumental support and Dr. Michael $\mathrm{N}$. Cocchi for constructing graphical abstract figures. We gratefully acknowledge Prof. Dr. Christopher Brown for proof reading the manuscript. Synchrotron beam time was awarded by the National Synchrotron Light Source (NSLS-II) under the merit-based proposal scheme.

\section{REFERENCES}

[1] Yu, P.; Wu, J.; Liu, S.; Xiong, J.; Jagadish, C.; Wang, Z. M.Design and Fabrication of Silicon Nanowires towards Efficient Solar Cells. Nano Today2016, 11, 704-737, 10.1016/j.nantod.2016.10.001

[2] Sandhu, S.; Fan, S.Current-Voltage Enhancement of a Single Coaxial Nanowire Solar Cell. ACS Photonics2015, 2, 1698-1704, 10.1021/acsphotonics.5b00236

[3] van Dam, D.; Van Hoof, N. J. J.; Cui, Y.; van Veldhoven, P. J.; Bakkers, E. P. A. M.; Gómez Rivas, J.; Haverkort, J. E. M.High-Efficiency Nanowire Solar Cells with Omnidirectionally Enhanced Absorption Due to Self-Aligned Indium-Tin-Oxide Mie Scatterers. ACS Nano2016, 10, 11414-11419, 10.1021/acsnano.6b06874

[4] Luo, S.; Yu, W. B.; He, Y.; Ouyang, G.Size-Dependent Optical Absorption Modulation of Si/Ge and Ge/Si Core/shell Nanowires with Different Cross-Sectional Geometries. Nanotechnology2015, 26, 085702, 10.1088/09574484/26/8/085702

[5] Yu, P.; Yao, Y.; Wu, J.; Niu, X.; Rogach, A. L.; Wang, Z.Effects of Plasmonic Metal Core-Dielectric Shell Nanoparticles on the Broadband Light Absorption Enhancement in Thin Film Solar Cells. Sci. Rep.2017, 7, 7696, 10.1038/s41598-017-08077-9

[6] Gouda, A. M.; Allam, N. K.; Swillam, M. A.Efficient Fabrication Methodology of Wide Angle Black Silicon for Energy Harvesting Applications. RSC Adv.2017, 7, 2697426982, 10.1039/C7RA03568C

[7] Branz, H. M.; Yost, V. E.; Ward, S.; Jones, K. M.; To, B. Stradins, P.Nanostructured Black Silicon and the Optical 
Reflectance of Graded-Density Surfaces. Appl. Phys. Lett.2009, 94, 231121, 10.1063/1.3152244

[8] Fazio, B.; Artoni, P.; Antonía latí, M.; D’Andrea, C.; Lo Faro, M. J.; Del Sorbo, S.; Pirotta, S.; Giuseppe Gucciardi, P.; Musumeci, P.; Salvatore Vasi, C.; Saija, R.; Galli, M.; Priolo, F.; Irrera, A.Strongly Enhanced Light Trapping in a TwoDimensional Silicon Nanowire Random Fractal Array. Light: Sci. Appl.2016, 5, e16062, 10.1038/lsa.2016.62

[9] Ko, M.-D.; Rim, T.; Kim, K.; Meyyappan, M.; Baek, C.-K.High Efficiency Silicon Solar Cell Based on Asymmetric Nanowire. Sci. Rep.2015, 5, 11646, 10.1038/srep11646

[10] Oh, J.; Yuan, H. C.; Branz, H. M.An 18.2\%-Efficient BlackSilicon Solar Cell Achieved through Control of Carrier Recombination in Nanostructures. Nat. Nanotechnol.2012, 7, 743-748, 10.1038/nnano.2012.166

[11] Lin, H.; Xiu, F.; Fang, M.; Yip, S.; Cheung, H. Y.; Wang, F.; Han, N.; Chan, K. S.; Wong, C. Y.; Ho, J. C.Rational Design of Inverted Nanopencil Arrays for Cost-Effective, Broadband, and Omnidirectional Light Harvesting. ACS Nano2014, 8, 3752-3760, 10.1021/nn500418x

[12] Garnett, E.; Yang, P.Light Trapping in Silicon Nanowire Solar Cells. Nano Lett.2010, 10, 1082-1087, 10.1021/nl100161z

[13] Misra, S.; Yu, L.; Foldyna, M.; Roca I Cabarrocas, P.High Efficiency and Stable Hydrogenated Amorphous Silicon Radial Junction Solar Cells Built on VLS-Grown Silicon Nanowires. Sol. Energy Mater. Sol. Cells2013, 118, 90-95, 10.1016/j.solmat.2013.07.036

[14] Kelzenberg, M. D.; Boettcher, S. W.; Petykiewicz, J. A.; Turner-Evans, D. B.; Putnam, M. C.; Warren, E. L.; Spurgeon, J. M.; Briggs, R. M.; Lewis, N. S.; Atwater, H. A.Enhanced Absorption and Carrier Collection in Si Wire Arrays for Photovoltaic Applications. Nat. Mater.2010, 9, 239-244, 10.1038/nmat2635

[15] Tian, B.; Zheng, X.; Kempa, T. J.; Fang, Y.; Yu, N.; Yu, G.; Huang, J.; Lieber, C. M.Coaxial Silicon Nanowires as Solar Cells and Nanoelectronic Power Sources. Nature2007, 449, 885-889, 10.1038/nature06181

[16] Razek, S. A.; Swillam, M. A.; Allam, N. K.Vertically Aligned Crystalline Silicon Nanowires with Controlled Diameters for Energy Conversion Applications: Experimental and Theoretical Insights. J. Appl. Phys.2014, 115, 194305, 10.1063/1.4876477

[17] Dhindsa, N.; Walia, J.; Saini, S. S.A Platform for Colorful Solar Cells with Enhanced Absorption. Nanotechnology2016, 27, 495203, 10.1088/0957-4484/27/49/495203

[18] Dhindsa, N.; Walia, J.; Pathirane, M.; Khodadad, I.; Wong, W. S.; Saini, S. S.Adjustable Optical Response of Amorphous Silicon Nanowires Integrated with Thin Films. Nanotechnology2016, 27, 145703, 10.1088/0957$4484 / 27 / 14 / 145703$

[19] Zhu, J.; Yu, Z.; Burkhard, G. F.; Hsu, C.-M.; Connor, S. T.; Xu, Y.; Wang, Q.; McGehee, M.; Fan, S.; Cui, Y.Optical Absorption Enhancement in Amorphous Silicon Nanowire and Nanocone Arrays. Nano Lett.2009, 9, 279-282, $10.1021 / \mathrm{nl} 802886 \mathrm{y}$

[20] Klinger, D.; Łusakowska, E.; Zymierska, D.Nano-Structure Formed by Nanosecond Laser Annealing on Amorphous Si Surface. Mater. Sci. Semicond. Process.2006, 9, 323-326, 10.1016/j.mssp.2006.01.027

[21] Kumar, P.; Krishna, M. G.; Bhattacharya, A.Excimer Laser Induced Nanostructuring of Silicon Surfaces. J. Nanosci. Nanotechnol.2009, 9, 3224-3232, 10.1166/jnn.2009.207

[22] Kumar, P.Surface Modulation of Silicon Surface by Excimer Laser at Laser Fluence below Ablation Threshold. Appl. Phys. A: Mater. Sci. Process.2010, 99, 245-250, 10.1007/s00339-009-5510-x

[23] Adikaari, A. A. D. T.; Silva, S. R. P.Thickness Dependence of Properties of Excimer Laser Crystallized Nano-Polycrystalline Silicon. J. Appl. Phys.2005, 97, 114305, 10.1063/1.1898444
[24]

Adikaari, A. A. D. T.; Dissanayake, D. M. N. M.; Hatton, R. A.; Silva, S. R. P.Efficient Laser Textured Nanocrystalline Silicon-Polymer Bilayer Solar Cells. Appl. Phys. Lett.2007, 90, 203514, 10.1063/1.2739365

[25] Adikaari, A. A. D. T.; Silva, S. R. P.Excimer Laser Crystallization and Nanostructuring of Amorphous Silicon for Photovoltaic Applications. Nano2008, 3, 117-126, 10.1142/S1793292008000915

[26] Tang, Y. F.; Silva, S. R. P.; Boskovic, B. O.; Shannon, J. M.; Rose, M. J.Electron Field Emission from Excimer Laser Crystallized Amorphous Silicon. Appl. Phys. Lett.2002, 80, 4154-4156, 10.1063/1.1482141

[27] Jin, S.; Hong, S.; Mativenga, M.; Kim, B.; Shin, H. H.; Park, J. K.; Kim, T. W.; Jang, J.Low Temperature Polycrystalline Silicon with Single Orientation on Glass by Blue Laser Annealing. Thin Solid Films2016, 616, 838-841, 10.1016/j.tsf.2016.10.026

[28] Crouch, C. H.; Carey, J. E.; Warrender, J. M.; Aziz, M. J.; Mazur, E.; Génin, F. Y.Comparison of Structure and Properties of Femtosecond and Nanosecond LaserStructured Silicon. Appl. Phys. Lett.2004, 84, 1850-1852, 10.1063/1.1667004

[29] Wu, C.; Crouch, C. H.; Zhao, L.; Carey, J. E.; Younkin, R.; Levinson, J. A.; Mazur, E.; Farrell, R. M.; Gothoskar, P.; Karger, A.Near-Unity below-Band-Gap Absorption by Microstructured Silicon. Appl. Phys. Lett.2001, 78, 18501852, 10.1063/1.1358846

[30] Pedraza, A. J.; Fowlkes, J. D.; Lowndes, D. H.Silicon Microcolumn Arrays Grown by Nanosecond Pulsed-Excimer Laser Irradiation. Appl. Phys. Lett.1999, 74, 2322 10.1063/1.123838

[31] Pedraza, A. J.; Fowlkes, J. D.; Jesse, S.; Mao, C.; Lowndes, D. H.Surface Micro-Structuring of Silicon by Excimer-Laser Irradiation in Reactive Atmospheres. Appl. Surf. Sci.2000, 168, 251-257, 10.1016/S0169-4332(00)00611-5

[32] Porte, H. P.; Turchinovich, D.; Persheyev, S.; Fan, Y.; Rose, M. J.; Jepsen, P. U.On Ultrafast Photoconductivity Dynamics and Crystallinity of Black Silicon. IEEE Trans. Terahertz Sci. Technol.2013, 3, 331-341, 10.1109/TTHZ.2013.2255917

[33] Georgiev, D. G.; Baird, R. J.; Avrutsky, I.; Auner, G.; Newaz, G.Controllable Excimer-Laser Fabrication of Conical NanoTips on Silicon Thin Films. Appl. Phys. Lett.2004, 84, 48814883, 10.1063/1.1762978

[34] Eizenkop, J.; Avrutsky, I.; Georgiev, D. G.; Chaudchary, V.Single-Pulse Excimer Laser Nanostructuring of Silicon: A Heat Transfer Problem and Surface Morphology. J. Appl. Phys.2008, 103, 094311, 10.1063/1.2910196

[35] Eizenkop, J.; Avrutsky, I.; Auner, G.; Georgiev, D. G.; Chaudhary, V.Single Pulse Excimer Laser Nanostructuring of Thin Silicon Films: Nanosharp Cones Formation and a Heat Transfer Problem. J. Appl. Phys.2007, 101, 094301, 10.1063/1.2720185

[36] Hong, L.; Wang, X. C.; Zheng, H. Y.; He, L.; Wang, H.; Yu, H. Y.; RusliFemtosecond Laser Induced Nanocone Structure and Simultaneous Crystallization of $1.6 \mu \mathrm{M}$ Amorphous Silicon Thin Film for Photovoltaic Application. J. Phys. D: Appl. Phys.2013, 46, 195109, 10.1088/00223727/46/19/195109

[37] Hong, L.; Wang, X.; Rusli; Wang, H.; Zheng, H.; Yu, H.Crystallization and Surface Texturing of Amorphous-Si Induced by UV Laser for Photovoltaic Application. J. Appl. Phys.2012, 111, 043106, 10.1063/1.3686612

[38] Magdi, S.; Swillam, M. A.Broadband Absorption Enhancement in Amorphous Si Solar Cells Using Metal Gratings and Surface Texturing. Proc. SPIE2017, 10099, 1009912, 10.1117/12.2253326

[39] Diedenhofen, S. L.; Janssen, O. T. A.; Grzela, G.; Bakkers, E. P. A. M.; Gómez Rivas, J.Strong Geometrical Dependence of the Absorption of Light in Arrays of 
Semiconductor Nanowires. ACS Nano2011, 5, 2316-2323, $10.1021 / \mathrm{nn} 103596 \mathrm{n}$

[40] Jäger, S. T.; Strehle, S.Design Parameters for Enhanced Photon Absorption in Vertically Aligned Silicon Nanowire Arrays. Nanoscale Res. Lett.2014, 9, 511, 10.1186/1556276X-9-511

[41] Gouda, A. M.; Elsayed, M. Y.; Khalifa, A. E.; Ismail, Y.; Swillam, M. A.Lithography-Free Wide-Angle Antireflective Self-Cleaning Silicon Nanocones. Opt. Lett.2016, 41, 3575, 10.1364/OL.41.003575

[42] Magdi, S.; Swillam, M. A.Optical Analysis of Si-Tapered Nanowires/low Band Gap Polymer Hybrid Solar Cells. Proc. SPIE2017, 10099, 100991D, 10.1117/12.2253299

[43] Jiang, Y.; Gong, X.; Qin, R.; Liu, H.; Xia, C.; Ma, H.Efficiency Enhancement Mechanism for Poly(3, 4ethylenedioxythiophene):Poly(styrenesulfonate)/Silicon Nanowires Hybrid Solar Cells Using Alkali Treatment. Nanoscale Res. Lett.2016, 11, 267, 10.1186/s11671-0161450-5

[44] Gong, X.; Jiang, Y.; Li, M.; Liu, H.; Ma, H.Hybrid Tapered Silicon nanowire/PEDOT:PSS Solar Cells. RSC Adv.2015, 5 (14), 10310-10317, 10.1039/C4RA16603E

[45] Mohammad, N. S.Understanding Quantum Confinement in Nanowires: Basics, Applications and Possible Laws. J. Phys.: Condens. Matter2014, 26, 423202, 10.1088/09538984/26/42/423202

[46] Zhang, A.; Luo, S.; Ouyang, G.; Yang, G. W.Strain-Induced Optical Absorption Properties of Semiconductor Nanocrystals. J. Chem. Phys.2013, 138, 244702, 10.1063/1.4811222

[47] He, Y.; Yu, W.; Ouyang, G.Shape-Dependent Conversion Efficiency of Si Nanowire Solar Cells with Polygonal CrossSections. J. Appl. Phys.2016, 119, 225101, 10.1063/1.4953377

[48] Tchakarov, S.; Das, D.; Saadane, O.; Kharchenko, A. V.; Suendo, V.; Kail, F.; Roca i Cabarrocas, P.Helium versus Hydrogen Dilution in the Optimization of Polymorphous Silicon Solar Cells. J. Non-Cryst. Solids2004, 338-340, 668672, 10.1016/j.jnoncrysol.2004.03.068

[49] Roszairi, H.; Rahman, S. a.High Deposition Rate Thin Film Hydrogenated Amorphous Silicon Prepared by D.c. Plasma Enhanced Chemical Vapour Deposition of Helium Diluted Silane. IEEE International Conference on Semiconductor Electronics, 2002. Proceedings. ICSE 2002, Panang, Malaysia, Dec. 19-21, 2002; IEEE: New York, NY, USA, 2002; pp 300-303, DOI: 10.1109/SMELEC.2002.1217830.

[50] N'Guyen, T. T. T.; Duong, H. T. T.; Basuki, J.; Montembault, V.; Pascual, S.; Guibert, C.; Fresnais, J.; Boyer, C.; Whittaker, M. R.; Davis, T. P.; Fontaine, L.Functional Iron Oxide Magnetic Nanoparticles with Hyperthermia-Induced Drug Release Ability by Using a Combination of Orthogonal Click Reactions. Angew. Chem., Int. Ed.2013, 52, 1415214156, 10.1002/anie.201306724

[51] Xu, Z.; Zhao, Y.; Wang, X.; Lin, T.A Thermally Healable Polyhedral Oligomeric Silsesquioxane (POSS) Nanocomposite based on Diels-Alder chemistry. Chem. Commun.2013, 49, 6755-6757, 10.1039/c3cc43432j

[52] Engel, T.; Kickelbick, G.Self-Healing Nanocomposites from Silica - Polymer Core - Shell Nanoparticles. Polym. Int.2014, 63, 915-923, 10.1002/pi.4642

[53] Engel, T.; Kickelbick, G.Furan-Modified Spherosilicates as Building Blocks for Self-Healing Materials. Eur. J. Inorg. Chem.2015, 2015, 1226-1232, 10.1002/ejic.201402551

[54] Torres-Lugo, M.; Rinaldi, C.Thermal Potentiation of Chemotherapy by Magnetic Nanoparticles. Nanomedicine2013, 8, 1689-1707, 10.2217/nnm.13.146

[55] Hohlbein, N.; Shaaban, A.; Bras, A. R.; Pyckhout-Hintzen, W.; Schmidt, A. M.Self-healing Dynamic Bond-based Rubbers: Understanding the Mechanisms in Ionomeric
Elastomer Model Systems. Phys. Chem. Chem. Phys.2015, 17, 21005-21017, 10.1039/C5CP00620A

[56] Wu, C.-S.; Kao, T.-H.; Li, H.-Y.; Liu, Y.-L.Preparation of Polybenzoxazine-functionalized $\mathrm{Fe} 3 \mathrm{O} 4 \quad$ Nanoparticles through in situ Diels-Alder Polymerization for High Performance Magnetic Polybenzoxazine/Fe3O4 Nanocomposites. Compos. Sci. Technol.2012, 72, 15621567, 10.1016/j.compscitech.2012.06.018

[57] Menon, A. V.; Madras, G.; Bose, S.Ultrafast Self-Healable Interfaces in Polyurethane Nanocomposites Designed Using Diels-Alder "Click" as an Efficient Microwave Absorber. ACS Omega2018, 3, 1137-1146, 10.1021/acsomega.7b01845

[58] Engel, T.; Kickelbick, G.Thermoreversible Reactions on Inorganic Nanoparticle Surfaces: Diels-Alder Reactions on Sterically Crowded Surfaces. Chem. Mater.2013, 25, 149$157,10.1021 / \mathrm{cm} 303049 \mathrm{k}$

[59] Schäfer, S.; Kickelbick, G.Self-Healing Polymer Nanocomposites based on Diels-Alder-reactions with Silica Nanoparticles: The Role of the Polymer Matrix. Polymer2015, 69, 357-368, 10.1016/j.polymer.2015.03.017

[60] Park, J. S.; Darlington, T.; Starr, A. F.; Takahashi, K.; Riendeau, J.; Thomas Hahn, H.Multiple Healing Effect of Thermally Activated Self-Healing Composites based on Diels-Alder reaction. Compos. Sci. Technol.2010, 70, 21542159, 10.1016/j.compscitech.2010.08.017

[61] Li, J.; Liang, J.; Li, L.; Ren, F.; Hu, W.; Li, J.; Qi, S.; Pei, Q.Healable Capacitive Touch Screen Sensors Based on Transparent Composite ElectrodesComprising Silver Nanowires and a Furan/Maleimide Diels-Alder Cycloaddition Polymer. ACS Nano2014, 8, 12874-12882, 10.1021/nn506610p

[62] Sun, S.; Zeng, H.; Robinson, D. B.; Raoux, S.; Rice, P. M.; Wang, S. X.; Li, G.Monodisperse MFe2O4 (M = Fe, Co, Mn) Nanoparticles. J. Am. Chem. Soc.2004, 126, 273-279, 10.1021/ja0380852

[63] Frison, R.; Cernuto, G.; Cervellino, A.; Zaharko, O.; Colonna, G. M.; Guagliardi, A.; Masciocchi, N.Magnetite-Maghemite Nanoparticles in the 5-15 nm Range: Correlating the CoreShell Composition and the Surface Structure to the Magnetic Properties. A Total Scattering Study. Chem. Mater.2013, 25, 4820-4827, 10.1021/cm403360f

[64] Santoyo Salazar, J.; Perez, L.; de Abril, O.; Truong Phuoc, L.; Ihiawakrim, D.; Vazquez, M.; Greneche, J.-M.; BeginColin, S.; Pourroy, G.Magnetic Iron Oxide Nanoparticles in 10-40 nm Range: Composition in Terms of Magnetite/Maghemite Ratio and Effect on the Magnetic Properties. Chem. Mater.2011, 23, 1379-1386, $10.1021 / \mathrm{cm} 103188 \mathrm{a}$

[65] Guerrero, G.; Mutin, P. H.; Vioux, A.Anchoring of Phosphonate and Phosphinate Coupling Molecules on Titania Particles. Chem. Mater.2001, 13, 4367-4373, 10.1021/cm001253u

[66] Babu, K.; Dhamodharan, R.Grafting of Poly(methy methacrylate) Brushes from Magnetite Nanoparticles Using a Phosphonic Acid Based Initiator by Ambient Temperature Atom Transfer Radical Polymerization (ATATRP). Nanoscale Res. Lett.2008, 3, 109-117, 10.1007/s11671-008-9121-9

[67] Mohapatra, S.; Pramanik, P.Synthesis and Stability of Functionalized Iron Oxide Nanoparticles using Organophosphorus Coupling Agents. Colloids Surf., A2009, 339, 35-42, 10.1016/j.colsurfa.2009.01.009

[68] Larsen, B. A.; Hurst, K. M.; Ashurst, W. R.; Serkova, N. J.; Stoldt, C. R.Mono- and Dialkoxysilane Surface Modification of Superparamagnetic Iron Oxide Nanoparticles for Application as Magnetic Resonance Imaging Contrast Agents. J. Mater. Res.2012, 27, 1846-1852, 10.1557/jmr.2012.160

[69] Davis, K.; Qi, B.; Witmer, M.; Kitchens, C. L.; Powell, B. A.; Mefford, O. T.Quantitative Measurement of Ligand Exchange 
on Iron Oxides via Radiolabeled Oleic Acid. Langmuir2014, 30, 10918-10925, 10.1021/la502204g

[70] Feichtenschlager, B.; Pabisch, S.; Peterlik, H.; Kickelbick, G.Nanoparticle Assemblies as Probes for Self-Assembled Monolayer Characterization: Correlation between Surface Functionalization and Agglomeration Behavior. Langmuir2012, 28, 741-750, 10.1021/la2023067

[71] Musa, O. M.Handbook of Maleic Anhydride Based Materials: Syntheses, Properties and Applications;Springer International Publishing: Switzerland, 2016; p $175 \mathrm{ff}$.

[72] Sauer, R.; Froimowicz, P.; Scholler, K.; Cramer, J. M.; Ritz, S.; Mailander, V.; Landfester, K.Design, Synthesis, and Miniemulsion Polymerization of New Phosphonate Surfmers and Application Studies of the Resulting Nanoparticles as Model Systems for Biomimetic Mineralization and Cellular Uptake. Chem. - Eur. J.2012, 18, 5201-5212, 10.1002/chem.201103256

[73] Lu, C.; Bhatt, L. R.; Jun, H. Y.; Park, S. H.; Chai, K. Y.Carboxyl-Polyethylene Glycol-Phosphoric Acid: A Ligand for highly stabilized Iron Oxide Nanoparticles. J. Mater. Chem.2012, 22, 19806-19811, 10.1039/c2jm34327d

[74] Patsula, V.; Kosinova, L.; Lovric, M.; Ferhatovic Hamzic, L.; Rabyk, M.; Konefal, R.; Paruzel, A.; Slouf, M.; Herynek, V.; Gajovic, S.; Horak, D.Superparamagnetic Fe3O4 Nanoparticles: Synthesis by Thermal Decomposition of Iron(III) Glucuronate and Application in Magnetic Resonance Imaging. ACS Appl. Mater. Interfaces2016, 8, 7238-7247, 10.1021/acsami.5b12720

[75] Pothayee, N.; Balasubramaniam, S.; Davis, R. M.; Riffle, J. S.; Carroll, M. R. J.; Woodward, R. C.; St Pierre, T. G.Synthesis of 'ready-to-adsorb' Polymeric Nanoshells for Magnetic Iron Oxide Nanoparticles via Atom Transfer Radical Polymerization. Polymer2011, 52, 1356-1366, 10.1016/j.polymer.2011.01.047

[76] Daou, J.; Begin-Colin, S.; Grenèche, J. M.; Thomas, F.; Derory, A.; Bernhardt, P.; Legaré, P.; Pourroy, G.Phosphate Adsorption Properties of Magnetite-Based Nanoparticles. Chem. Mater.2007, 19, 4494-4505, 10.1021/cm071046v

[77] Breucker, L.; Landfester, K.; Taden, A.Phosphonic AcidFunctionalized Polyurethane Dispersions with Improved Adhesion Properties. ACS Appl. Mater. Interfaces2015, 7, 24641-24648, 10.1021/acsami.5b06903

[78] Sahoo, Y.; Pizem, H.; Fried, T.; Golodnitsky, D.; Burstein, L.; Sukenik, C. N.; Markovich, G.Alkyl Phosphonate/Phosphate Coating on Magnetite Nanoparticles: A Comparison with Fatty Acids. Langmuir2001, 17, 7907-7911, 10.1021/la010703+

[79] Longo, R. C.; Cho, K.; Schmidt, W. G.; Chabal, Y. J.; Thissen, P.Monolayer Doping via Phosphonic Acid Grafting on Silicon: Microscopic Insight from Infrared Spectroscopy and Density Functional Theory Calculations. Adv. Funct. Mater.2013, 23, 3471-3477, 10.1002/adfm.201202808

[80] Luschtinetz, R.; Seifert, G.; Jaehne, E.; Adler, H.-J. P.Infrared Spectra of Alkylphosphonic Acid Bound to Aluminium Surfaces. Macromol. Symp.2007, 254, 248-253, 10.1002/masy.200750837

[81] Thomas, L. C.; Chittenden, R. A.Characteristic Infrared Absorption Frequencies of Organophosphorus CompoundsII. P-O-(X) Bonds. Spectrochim. Acta1964, 20, 489-502, 10.1016/0371-1951(64)80044-8

[82] Quinones, R.; Shoup, D.; Behnke, G.; Peck, C.; Agarwal, S.; Gupta, R. K.; Fagan, J. W.; Mueller, K. T.; Iuliucci, R. J.; Wang, Q.Study of Perfluorophosphonic Acid Surface Modifications on Zinc Oxide Nanoparticles. Materials2017, 10, 1-16, 10.3390/ma10121363

[83] Lalatonne, Y.; Paris, C.; Serfaty, J. M.; Weinmann, P.; Lecouvey, M.; Motte, L.Bis-Phosphonates-Ultra Small Superparamagnetic Iron Oxide Nanoparticles: A Platform towards Diagnosis and Therapy. Chem. Commun.2008, 2553-2555, 10.1039/b801911h

[84] Jastrzebski, W.; Sitarz, M.; Rokita, M.; Bulat, K.Infrared Spectroscopy of different Phosphates Structures. Spectrochim. Acta, Part A2011, 79, 722-727, 10.1016/j.saa.2010.08.044

[85] Brodard-Severac, F.; Guerrero, G.; Maquet, J.; Florian, P.; Gervais, C.; Mutin, P. H.High-Field 170 MAS NMR Investigation of Phosphonic Acid Monolayers on Titania. Chem. Mater.2008, 20, 5191-5196, 10.1021/cm8012683

[86] Brice-Profeta, S.; Arrio, M. A.; Tronc, E.; Menguy, N.; Letard, I.; CartierditMoulin, C.; Noguès, M.; Chanéac, C.; Jolivet, J. P.; Sainctavit, P.Magnetic Order in g-Fe2O3 Nanoparticles: A XMCD Study. J. Magn. Magn. Mater.2005, 288, 354-365, 10.1016/j.jmmm.2004.09.120

[87] Tronc, E.; Ezzir, A.; Cherkaoui, R.; Chanéac, C.; Noguès, M.; Kachkachi, H.; Fiorani, D.; Testa, A. M.; Grenèche, J. M.; Jolivet, J. P.Surface-Related Properties of g-Fe2O3 Nanoparticles. J. Magn. Magn. Mater.2000, 221, 63-79, 10.1016/S0304-8853(00)00369-3

[88] Yee, C.; Kataby, G.; Ulman, A.; Prozorov, T.; White, H.; King, A.; Rafailovich, M.; Sokolov, J.; Gedanken, A.Self-Assembled Monolayers of Alkanesulfonic and -phosphonic Acids on Amorphous Iron Oxide Nanoparticles. Langmuir1999, 15, 7111-7115, 10.1021/la990663y

[89] Jolivet, J. P.; Chaneac, C.; Tronc, E.Iron Oxide Chemistry. From Molecular Clusters to Extended Solid Networks. Chem. Commun.2004, 481-487, 10.1039/B304532N

[90] Campbell, V. E.; Tonelli, M.; Cimatti, I.; Moussy, J. B.; Tortech, L.; Dappe, Y. J.; Riviere, E.; Guillot, R.; Delprat, S.; Mattana, R.; Seneor, P.; Ohresser, P.; Choueikani, F.; Otero, E.; Koprowiak, F.; Chilkuri, V. G.; Suaud, N.; Guihery, N.; Galtayries, A.; Miserque, F.; Arrio, M. A.; Sainctavit, P.; Mallah, T.Engineering the Magnetic Coupling and Anisotropy at the Molecule-Magnetic Surface Interface in Molecular Spintronic Devices. Nat. Commun.2016, 7, 13646-10, 10.1038/ncomms 13646

[91] Pabisiak, T.; Winiarski, M. J.; Ossowski, T.; Kiejna, A.Adsorption of Gold Subnano-Structures on a Magnetite (111) Surface and their Interaction with CO. Phys. Chem. Chem. Phys.2016, 18, 18169-18179, 10.1039/C6CP03222B

[92] Gomes, R.; Hassinen, A.; Szczygiel, A.; Zhao, Q.; Vantomme, A.; Martins, J. C.; Hens, Z.Binding of Phosphonic Acids to CdSe Quantum Dots: A Solution NMR Study. J. Phys. Chem. Lett.2011, 2, 145-152, 10.1021/jz1016729

[93] Chun, Y.-J.; Park, J.-N.; Oh, G.-M.; Hong, S.-I.; Kim, Y.J.Synthesis of $\omega$-Phthalimidoalkylphosphonates. Synthesis1994, 1994, 909-910, 10.1055/s-1994-25599

[94] A. Heidari, C. Brown, "Study of Composition and Morphology of Cadmium Oxide (CdO) Nanoparticles for Eliminating Cancer Cells", J Nanomed Res., Volume 2, Issue 5, 20 Pages, 2015.

[95] A. Heidari, C. Brown, "Study of Surface Morphological, Phytochemical and Structural Characteristics of Rhodium (III) Oxide $\left(\mathrm{Rh}_{2} \mathrm{O}_{3}\right)$ Nanoparticles", International Journal of Pharmacology, Phytochemistry and Ethnomedicine, Volume 1, Issue 1, Pages 15-19, 2015.

[96] A. Heidari, "An Experimental Biospectroscopic Study on Seminal Plasma in Determination of Semen Quality for Evaluation of Male Infertility", Int J Adv Technol 7: e007, 2016.

[97] A. Heidari, "Extraction and Preconcentration of N-TolylSulfonyl-Phosphoramid-Saeure-Dichlorid as an AntiCancer Drug from Plants: A Pharmacognosy Study", J Pharmacogn Nat Prod 2: e103, 2016.

[98] A. Heidari, "A Thermodynamic Study on Hydration and Dehydration of DNA and RNA-Amphiphile Complexes", J Bioeng Biomed Sci S: 006, 2016. 
[99] A. Heidari, "Computational Studies on Molecular Structures and Carbonyl and Ketene Groups' Effects of Singlet and Triplet Energies of Azidoketene $\mathrm{O}=\mathrm{C}=\mathrm{CH}-\mathrm{NNN}$ and Isocyanatoketene $\mathrm{O}=\mathrm{C}=\mathrm{CH}-\mathrm{N}=\mathrm{C}=\mathrm{O}$ ", J Appl Computat Math 5: e142, 2016

[100] A. Heidari, "Study of Irradiations to Enhance the Induces the Dissociation of Hydrogen Bonds between Peptide Chains and Transition from Helix Structure to Random Coil Structure Using ATR-FTIR, Raman and ${ }^{1}$ HNMR Spectroscopies", J Biomol Res Ther 5: e146, 2016.

[101] A. Heidari, "Future Prospects of Point Fluorescence Spectroscopy, Fluorescence Imaging and Fluorescence Endoscopy in Photodynamic Therapy (PDT) for Cancer Cells", J Bioanal Biomed 8: e135, 2016.

[102] A. Heidari, "A Bio-Spectroscopic Study of DNA Density and Color Role as Determining Factor for Absorbed Irradiation in Cancer Cells", Adv Cancer Prev 1: e102, 2016.

[103] A. Heidari, "Manufacturing Process of Solar Cells Using Cadmium Oxide (CdO) and Rhodium (III) Oxide $\left(\mathrm{Rh}_{2} \mathrm{O}_{3}\right)$ Nanoparticles", J Biotechnol Biomater 6: e125, 2016.

[104] A. Heidari, "A Novel Experimental and Computational Approach to Photobiosimulation of Telomeric DNA/RNA: A Biospectroscopic and Photobiological Study", J Res Development 4: 144, 2016.

[105] A. Heidari, "Biochemical and Pharmacodynamical Study of Microporous Molecularly Imprinted Polymer Selective for Vancomycin, Teicoplanin, Oritavancin, Telavancin and Dalbavancin Binding", Biochem Physiol 5: e146, 2016.

[106] A. Heidari, "Anti-Cancer Effect of UV Irradiation at Presence of Cadmium Oxide (CdO) Nanoparticles on DNA of Cancer Cells: A Photodynamic Therapy Study", Arch Cancer Res. 4: 1, 2016.

[107] A. Heidari, "Biospectroscopic Study on Multi-Component Reactions (MCRs) in Two A-Type and B-Type Conformations of Nucleic Acids to Determine Ligand Binding Modes, Binding Constant and Stability of Nucleic Acids in Cadmium Oxide (CdO) Nanoparticles-Nucleic Acids Complexes as Anti-Cancer Drugs", Arch Cancer Res. 4: 2, 2016.

[108] A. Heidari, "Simulation of Temperature Distribution of DNA/RNA of Human Cancer Cells Using Time-Dependent Bio-Heat Equation and Nd: YAG Lasers", Arch Cancer Res. 4: 2, 2016.

[109] A. Heidari, "Quantitative Structure-Activity Relationship (QSAR) Approximation for Cadmium Oxide (CdO) and Rhodium (III) Oxide $\left(\mathrm{Rh}_{2} \mathrm{O}_{3}\right)$ Nanoparticles as Anti-Cancer Drugs for the Catalytic Formation of Proviral DNA from Viral RNA Using Multiple Linear and Non-Linear Correlation Approach", Ann Clin Lab Res. 4: 1, 2016.

[110] A. Heidari, "Biomedical Study of Cancer Cells DNA Therapy Using Laser Irradiations at Presence of Intelligent Nanoparticles", J Biomedical Sci. 5: 2, 2016.

[111] A. Heidari, "Measurement the Amount of Vitamin D2 (Ergocalciferol), Vitamin D3 (Cholecalciferol) and Absorbable Calcium $\left(\mathrm{Ca}^{2+}\right)$, Iron (II) $\left(\mathrm{Fe}^{2+}\right)$, Magnesium $\left(\mathrm{Mg}^{2+}\right)$, Phosphate $\left(\mathrm{PO}^{4-}\right)$ and Zinc $\left(\mathrm{Zn}^{2+}\right)$ in Apricot Using HighPerformance Liquid Chromatography (HPLC) and Spectroscopic Techniques", J Biom Biostat 7: 292, 2016.

[112] A. Heidari, "Spectroscopy and Quantum Mechanics of the Helium Dimer $\left(\mathrm{He}^{2+}\right)$, Neon Dimer $\left(\mathrm{Ne}^{2+}\right)$, Argon Dimer $\left(\mathrm{Ar}^{2+}\right)$, Krypton Dimer $\left(\mathrm{Kr}^{2+}\right)$, Xenon Dimer $\left(\mathrm{Xe}^{2+}\right)$, Radon Dimer $\left(\mathrm{Rn}^{2+}\right)$ and Ununoctium Dimer $\left(\mathrm{Uuo}^{2+}\right)$ Molecular Cations", Chem Sci J 7: e112, 2016.

[113] A. Heidari, "Human Toxicity Photodynamic Therapy Studies on DNA/RNA Complexes as a Promising New Sensitizer for the Treatment of Malignant Tumors Using Bio-Spectroscopic Techniques", J Drug Metab Toxicol 7: e129, 2016.

[114] A. Heidari, "Novel and Stable Modifications of Intelligent Cadmium Oxide (CdO) Nanoparticles as Anti-Cancer Drug in
Formation of Nucleic Acids Complexes for Human Cancer Cells' Treatment", Biochem Pharmacol (Los Angel) 5: 207, 2016.

[115] A. Heidari, "A Combined Computational and QM/MM Molecular Dynamics Study on Boron Nitride Nanotubes (BNNTs), Amorphous Boron Nitride Nanotubes (a-BNNTs) and Hexagonal Boron Nitride Nanotubes (h-BNNTs) as Hydrogen Storage", Struct Chem Crystallogr Commun 2: 1, 2016.

[116] A. Heidari, "Pharmaceutical and Analytical Chemistry Study of Cadmium Oxide (CdO) Nanoparticles Synthesis Methods and Properties as Anti-Cancer Drug and its Effect on Human Cancer Cells", Pharm Anal Chem Open Access 2: 113, 2016

[117] A. Heidari, "A Chemotherapeutic and Biospectroscopic Investigation of the Interaction of Double-Standard DNA/RNA-Binding Molecules with Cadmium Oxide (CdO) and Rhodium (III) Oxide $\left(\mathrm{Rh}_{2} \mathrm{O}_{3}\right)$ Nanoparticles as AntiCancer Drugs for Cancer Cells' Treatment", Chemo Open Access 5: e129, 2016.

[118] A. Heidari, "Pharmacokinetics and Experimental Therapeutic Study of DNA and Other Biomolecules Using Lasers: Advantages and Applications", J Pharmacokinet Exp Ther 1: e005, 2016.

[119] A. Heidari, "Determination of Ratio and Stability Constant of DNA/RNA in Human Cancer Cells and Cadmium Oxide (CdO) Nanoparticles Complexes Using Analytical Electrochemical and Spectroscopic Techniques", Insights Anal Electrochem 2: 1, 2016.

[120] A. Heidari, "Discriminate between Antibacterial and NonAntibacterial Drugs Artificial Neutral Networks of a Multilayer Perceptron (MLP) Type Using a Set of Topological Descriptors", J Heavy Met Toxicity Dis. 1: 2, 2016.

[121] A. Heidari, "Combined Theoretical and Computational Study of the Belousov-Zhabotinsky Chaotic Reaction and Curtius Rearrangement for Synthesis of Mechlorethamine, Cisplatin, Streptozotocin, Cyclophosphamide, Melphalan, Busulphan and BCNU as Anti-Cancer Drugs", Insights Med Phys. 1: 2, 2016.

[122] A. Heidari, "A Translational Biomedical Approach to Structural Arrangement of Amino Acids' Complexes: A Combined Theoretical and Computational Study", Transl Biomed. 7: 2, 2016.

[123] A. Heidari, "Ab Initio and Density Functional Theory (DFT) Studies of Dynamic NMR Shielding Tensors and Vibrational Frequencies of DNA/RNA and Cadmium Oxide (CdO) Nanoparticles Complexes in Human Cancer Cells", J Nanomedine Biotherapeutic Discov 6: e144, 2016.

[124] A. Heidari, "Molecular Dynamics and Monte-Carlo Simulations for Replacement Sugars in Insulin Resistance, Obesity, LDL Cholesterol, Triglycerides, Metabolic Syndrome, Type 2 Diabetes and Cardiovascular Disease: A Glycobiological Study", J Glycobiol 5: e111, 2016.

[125] A. Heidari, "Synthesis and Study of 5[(Phenylsulfonyl)Amino]-1,3,4-Thiadiazole-2-Sulfonamide as Potential Anti-Pertussis Drug Using Chromatography and Spectroscopy Techniques", TransI Med (Sunnyvale) 6: e138, 2016.

[126] A. Heidari, "Nitrogen, Oxygen, Phosphorus and Sulphur Heterocyclic Anti-Cancer Nano Drugs Separation in the Supercritical Fluid of Ozone $\left(\mathrm{O}_{3}\right)$ Using Soave-RedlichKwong (SRK) and Pang-Robinson (PR) Equations", Electronic J Biol 12: 4, 2016.

[127] A. Heidari, "An Analytical and Computational Infrared Spectroscopic Review of Vibrational Modes in Nucleic Acids", Austin J Anal Pharm Chem. 3 (1): 1058, 2016.

[128] A. Heidari, C. Brown, "Phase, Composition and Morphology Study and Analysis of Os-Pd/HfC Nanocomposites", Nano Res Appl. 2: 1, 2016. 
[129] A. Heidari, C. Brown, "Vibrational Spectroscopic Study of Intensities and Shifts of Symmetric Vibration Modes of Ozone Diluted by Cumene", International Journal of Advanced Chemistry, 4 (1) 5-9, 2016.

[130] A. Heidari, "Study of the Role of Anti-Cancer Molecules with Different Sizes for Decreasing Corresponding Bulk Tumor Multiple Organs or Tissues", Arch Can Res. 4: 2, 2016.

[131] A. Heidari, "Genomics and Proteomics Studies of Zolpidem, Necopidem, Alpidem, Saripidem, Miroprofen, Zolimidine, Olprinone and Abafungin as Anti-Tumor, Peptide Antibiotics, Antiviral and Central Nervous System (CNS) Drugs", J Data Mining Genomics \& Proteomics 7: e125, 2016.

[132] A. Heidari, "Pharmacogenomics and Pharmacoproteomics Studies of Phosphodiesterase-5 (PDE5) Inhibitors and Paclitaxel Albumin-Stabilized Nanoparticles as Sandwiched Anti-Cancer Nano Drugs between Two DNA/RNA Molecules of Human Cancer Cells", J Pharmacogenomics Pharmacoproteomics 7: e153, 2016.

[133] A. Heidari, "Biotranslational Medical and Biospectroscopic Studies of Cadmium Oxide (CdO) Nanoparticles-DNA/RNA Straight and Cycle Chain Complexes as Potent Anti-Viral, Anti-Tumor and Anti-Microbial Drugs: A Clinical Approach", Transl Biomed. 7: 2, 2016.

[134] A. Heidari, "A Comparative Study on Simultaneous Determination and Separation of Adsorbed Cadmium Oxide (CdO) Nanoparticles on DNA/RNA of Human Cancer Cells Using Biospectroscopic Techniques and Dielectrophoresis (DEP) Method", Arch Can Res. 4: 2, 2016.

[135] A. Heidari, "Cheminformatics and System Chemistry of Cisplatin, Carboplatin, Nedaplatin, Oxaliplatin, Heptaplatin and Lobaplatin as Anti-Cancer Nano Drugs: A Combined Computational and Experimental Study", J Inform Data Min 1: 3, 2016.

[136] A. Heidari, "Linear and Non-Linear Quantitative StructureAnti-Cancer-Activity Relationship (QSACAR) Study of Hydrous Ruthenium (IV) Oxide $\left(\mathrm{RuO}_{2}\right)$ Nanoparticles as Non-Nucleoside Reverse Transcriptase Inhibitors (NNRTIs) and Anti-Cancer Nano Drugs", J Integr Oncol 5: e110, 2016.

[137] A. Heidari, "Synthesis, Characterization and Biospectroscopic Studies of Cadmium Oxide (CdO) Nanoparticles-Nucleic Acids Complexes Absence of Soluble Polymer as a Protective Agent Using Nucleic Acids Condensation and Solution Reduction Method", J Nanosci Curr Res 1: e101, 2016.

[138] A. Heidari, "Coplanarity and Collinearity of 4'-Dinonyl-2,2'Bithiazole in One Domain of Bleomycin and Pingyangmycin to be Responsible for Binding of Cadmium Oxide (CdO) Nanoparticles to DNA/RNA Bidentate Ligands as Anti-Tumor Nano Drug", Int J Drug Dev \& Res 8: 007-008, 2016.

[139] A. Heidari, "A Pharmacovigilance Study on Linear and NonLinear Quantitative Structure (Chromatographic) Retention Relationships (QSRR) Models for the Prediction of Retention Time of Anti-Cancer Nano Drugs under Synchrotron Radiations", J Pharmacovigil 4: e161, 2016.

[140] A. Heidari, "Nanotechnology in Preparation of Semipermeable Polymers", J Adv Chem Eng 6: 157, 2016.

[141] A. Heidari, "A Gastrointestinal Study on Linear and NonLinear Quantitative Structure (Chromatographic) Retention Relationships (QSRR) Models for Analysis 5Aminosalicylates Nano Particles as Digestive System Nano Drugs under Synchrotron Radiations", J Gastrointest Dig Syst 6: e119, 2016.

[142] A. Heidari, "DNA/RNA Fragmentation and Cytolysis in Human Cancer Cells Treated with Diphthamide Nano Particles Derivatives", Biomedical Data Mining 5: e102, 2016.

[143] A. Heidari, "A Successful Strategy for the Prediction of Solubility in the Construction of Quantitative StructureActivity Relationship (QSAR) and Quantitative StructureProperty Relationship (QSPR) under Synchrotron Radiations
Using Genetic Function Approximation (GFA) Algorithm", J Mol Biol Biotechnol 1: 1, 2016.

[144] A. Heidari, "Computational Study on Molecular Structures of $\mathrm{C}_{20}, \mathrm{C}_{60}, \mathrm{C}_{240}, \mathrm{C}_{540}, \mathrm{C}_{960}, \mathrm{C}_{2160}$ and $\mathrm{C}_{3840}$ Fullerene Nano Molecules under Synchrotron Radiations Using Fuzzy Logic", J Material Sci Eng 5: 282, 2016.

[145] A. Heidari, "Graph Theoretical Analysis of Zigzag Polyhexamethylene Biguanide, Polyhexamethylene Adipamide, Polyhexamethylene Biguanide Gauze and Polyhexamethylene Biguanide Hydrochloride (PHMB) Boron Nitride Nanotubes (BNNTs), Amorphous Boron Nitride Nanotubes (a-BNNTs) and Hexagonal Boron Nitride Nanotubes (h-BNNTs)", J Appl Computat Math 5: e143, 2016.

[146] A. Heidari, "The Impact of High Resolution Imaging on Diagnosis", Int J Clin Med Imaging 3: 1000e101, 2016.

[147] A. Heidari, "A Comparative Study of Conformational Behavior of Isotretinoin (13-Cis Retinoic Acid) and Tretinoin (All-Trans Retinoic Acid (ATRA)) Nano Particles as Anti-Cancer Nano Drugs under Synchrotron Radiations Using Hartree-Fock (HF) and Density Functional Theory (DFT) Methods", Insights in Biomed 1: 2, 2016.

[148] A. Heidari, "Advances in Logic, Operations and Computational Mathematics", J Appl Computat Math 5: 5, 2016.

[149] A. Heidari, "Mathematical Equations in Predicting Physical Behavior", J Appl Computat Math 5: 5, 2016.

[150] A. Heidari, "Chemotherapy a Last Resort for Cancer Treatment", Chemo Open Access 5: 4, 2016.

[151] A. Heidari, "Separation and Pre-Concentration of Metal Cations-DNA/RNA Chelates Using Molecular Beam Mass Spectrometry with Tunable Vacuum Ultraviolet (VUV) Synchrotron Radiation and Various Analytical Methods", Mass Spectrom Purif Tech 2: e101, 2016.

[152] A. Heidari, "Yoctosecond Quantitative Structure-Activity Relationship (QSAR) and Quantitative Structure-Property Relationship (QSPR) under Synchrotron Radiations Studies for Prediction of Solubility of Anti-Cancer Nano Drugs in Aqueous Solutions Using Genetic Function Approximation (GFA) Algorithm", Insight Pharm Res. 1: 1, 2016.

[153] A. Heidari, "Cancer Risk Prediction and Assessment in Human Cells under Synchrotron Radiations Using Quantitative Structure Activity Relationship (QSAR) and Quantitative Structure Properties Relationship (QSPR) Studies", Int J Clin Med Imaging 3: 516, 2016.

[154] A. Heidari, "A Novel Approach to Biology", Electronic J Biol 12: 4, 2016.

[155] A. Heidari, "Innovative Biomedical Equipment's for Diagnosis and Treatment", J Bioengineer \& Biomedical Sci 6: 2, 2016.

[156] A. Heidari, "Integrating Precision Cancer Medicine into Healthcare, Medicare Reimbursement Changes and the Practice of Oncology: Trends in Oncology Medicine and Practices", J Oncol Med \& Pract 1: 2, 2016.

[157] A. Heidari, "Promoting Convergence in Biomedical and Biomaterials Sciences and Silk Proteins for Biomedical and Biomaterials Applications: An Introduction to Materials in Medicine and Bioengineering Perspectives", J Bioengineer \& Biomedical Sci 6: 3, 2016.

[158] A. Heidari, "X-Ray Fluorescence and X-Ray Diffraction Analysis on Discrete Element Modeling of Nano Powder Metallurgy Processes in Optimal Container Design", J Powder Metall Min 6: 1, 2017.

[159] A. Heidari, "Biomolecular Spectroscopy and Dynamics of Nano-Sized Molecules and Clusters as Cross-LinkingInduced Anti-Cancer and Immune-Oncology Nano Drugs Delivery in DNA/RNA of Human Cancer Cells' Membranes under Synchrotron Radiations: A Payload-Based Perspective", Arch Chem Res. 1: 2, 2017. 
[160] A. Heidari, "Deficiencies in Repair of Double-Standard DNA/RNA-Binding Molecules Identified in Many Types of Solid and Liquid Tumors Oncology in Human Body for Advancing Cancer Immunotherapy Using Computer Simulations and Data Analysis: Number of Mutations in a Synchronous Tumor Varies by Age and Type of Synchronous Cancer", J Appl Bioinforma Comput Biol, 6: 1, 2017.

[161] A. Heidari, "Electronic Coupling among the Five Nanomolecules Shuts Down Quantum Tunneling in the Presence and Absence of an Applied Magnetic Field for Indication of the Dimer or other Provide Different Influences on the Magnetic Behavior of Single Molecular Magnets (SMMs) as Qubits for Quantum Computing”, Glob J Res Rev. 4: 2, 2017.

[162] A. Heidari, "Polymorphism in Nano-Sized Graphene Ligand-

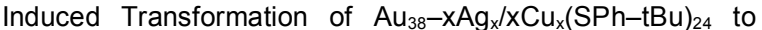
$\mathrm{Au}_{36}-\mathrm{xAg} \times \mathrm{x} / \mathrm{xCu}(\mathrm{SPh}-\mathrm{tBu})_{24}(\mathrm{x}=1-12)$ Nanomolecules for Synthesis of $\mathrm{Au}_{144}-\mathrm{xAg}_{\mathrm{x}} / \mathrm{xCu}_{\mathrm{x}}\left[(\mathrm{SR})_{60}, \quad\left(\mathrm{SC}_{4}\right)_{60}, \quad\left(\mathrm{SC}_{6}\right)_{60}\right.$, $\left(\mathrm{SC}_{12}\right)_{60},(\mathrm{PET})_{60},(\mathrm{p}-\mathrm{MBA})_{60},(\mathrm{~F})_{60},(\mathrm{Cl})_{60},(\mathrm{Br})_{60},(\mathrm{I})_{60},(\mathrm{At})_{60}$, (Uus) $)_{60}$ and $\left.\left(\mathrm{SC}_{6} \mathrm{H}_{13}\right)_{60}\right]$ Nano Clusters as Anti-Cancer Nano Drugs", J Nanomater Mol Nanotechnol, 6: 3, 2017.

[163] A. Heidari, "Biomedical Resource Oncology and Data Mining to Enable Resource Discovery in Medical, Medicinal, Clinical, Pharmaceutical, Chemical and Translational Research and Their Applications in Cancer Research", Int J Biomed Data Min 6: e103, 2017.

[164] A. Heidari, "Study of Synthesis, Pharmacokinetics, Pharmacodynamics, Dosing, Stability, Safety and Efficacy of Olympiadane Nanomolecules as Agent for Cancer Enzymotherapy, Immunotherapy, Chemotherapy, Radiotherapy, Hormone Therapy and Targeted Therapy under Synchrotorn Radiation", J Dev Drugs 6: e154, 2017.

[165] A. Heidari, "A Novel Approach to Future Horizon of Top Seven Biomedical Research Topics to Watch in 2017: Alzheimer's, Ebola, Hypersomnia, Human Immunodeficiency Virus (HIV), Tuberculosis (TB), Microbiome/Antibiotic Resistance and Endovascular Stroke", J Bioengineer \& Biomedical Sci 7: e127, 2017.

[166] A. Heidari, "Opinion on Computational Fluid Dynamics (CFD) Technique", Fluid Mech Open Acc 4: 157, 2017.

[167] A. Heidari, "Concurrent Diagnosis of Oncology Influence Outcomes in Emergency General Surgery for Colorectal Cancer and Multiple Sclerosis (MS) Treatment Using Magnetic Resonance Imaging (MRI) and $\mathrm{Au}_{329}(\mathrm{SR})_{84}, \mathrm{Au}_{329-}$ ${ }_{x} A_{x}(\mathrm{SR})_{84}, \mathrm{Au}_{144}(\mathrm{SR})_{60}, \mathrm{Au}_{68}(\mathrm{SR})_{36}, \mathrm{Au}_{30}(\mathrm{SR})_{18}, \mathrm{Au}_{102}(\mathrm{SPh})_{44}$, $\mathrm{Au}_{38}(\mathrm{SPh})_{24}, \mathrm{Au}_{38}\left(\mathrm{SC}_{2} \mathrm{H}_{4} \mathrm{Ph}\right)_{24}, \mathrm{Au}_{21} \mathrm{~S}(\mathrm{SAdm})_{15}, \mathrm{Au}_{36}(\mathrm{pMBA})_{24}$ and $\mathrm{Au}_{25}(\mathrm{pMBA})_{18}$ Nano Clusters", J Surgery Emerg Med1: 21, 2017.

[168] A. Heidari, "Developmental Cell Biology in Adult Stem Cells Death and Autophagy to Trigger a Preventive Allergic Reaction to Common Airborne Allergens under Synchrotron Radiation Using Nanotechnology for Therapeutic Goals in Particular Allergy Shots (Immunotherapy)", Cell Biol (Henderson, NV) 6: 1, 2017.

[169] A. Heidari, "Changing Metal Powder Characteristics for Elimination of the Heavy Metals Toxicity and Diseases in Disruption of Extracellular Matrix (ECM) Proteins Adjustment in Cancer Metastases Induced by Osteosarcoma, Chondrosarcoma, Carcinoid, Carcinoma, Ewing's Sarcoma, Fibrosarcoma and Secondary Hematopoietic Solid or Soft Tissue Tumors", J Powder Metall Min 6: 170, 2017.

[170] A. Heidari, "Nanomedicine-Based Combination Anti-Cancer Therapy between Nucleic Acids and Anti-Cancer Nano Drugs in Covalent Nano Drugs Delivery Systems for Selective Imaging and Treatment of Human Brain Tumors Using Hyaluronic Acid, Alguronic Acid and Sodium Hyaluronate as Anti-Cancer Nano Drugs and Nucleic Acids Delivery under Synchrotron Radiation", Am J Drug Deliv 5: 2, 2017.
[171] A. Heidari, "Clinical Trials of Dendritic Cell Therapies for Cancer Exposing Vulnerabilities in Human Cancer Cells' Metabolism and Metabolomics: New Discoveries, Unique Features Inform New Therapeutic Opportunities, Biotech's Bumpy Road to the Market and Elucidating the Biochemical Programs that Support Cancer Initiation and Progression", J Biol Med Science 1: e103, 2017.

[172] A. Heidari, "The Design Graphene-Based Nanosheets as a New Nanomaterial in Anti-Cancer Therapy and Delivery of Chemotherapeutics and Biological Nano Drugs for Liposomal Anti-Cancer Nano Drugs and Gene Delivery", Br Biomed Bull 5: 305, 2017.

[173] A. Heidari, "Integrative Approach to Biological Networks for Emerging Roles of Proteomics, Genomics and Transcriptomics in the Discovery and Validation of Human Colorectal Cancer Biomarkers from DNA/RNA Sequencing Data under Synchrotron Radiation", Transcriptomics 5: e117, 2017.

[174] A. Heidari, "Elimination of the Heavy Metals Toxicity and Diseases in Disruption of Extracellular Matrix (ECM) Proteins and Cell Adhesion Intelligent Nanomolecules Adjustment in Cancer Metastases Using Metalloenzymes and under Synchrotron Radiation", Lett Health Biol Sci 2 (2): 1-4, 2017.

[175] A. Heidari, "Treatment of Breast Cancer Brain Metastases through a Targeted Nanomolecule Drug Delivery System Based on Dopamine Functionalized Multi-Wall Carbon Nanotubes (MWCNTs) Coated with Nano Graphene Oxide (GO) and Protonated Polyaniline (PANI) in Situ During the Polymerization of Aniline Autogenic Nanoparticles for the Delivery of Anti-Cancer Nano Drugs under Synchrotron Radiation", Br J Res, 4 (3): 16, 2017.

[176] A. Heidari, "Sedative, Analgesic and Ultrasound-Mediated Gastrointestinal Nano Drugs Delivery for Gastrointestinal Endoscopic Procedure, Nano Drug-Induced Gastrointestinal Disorders and Nano Drug Treatment of Gastric Acidity", Res Rep Gastroenterol, 1: 1, 2017.

[177] A. Heidari, "Synthesis, Pharmacokinetics, Pharmacodynamics, Dosing, Stability, Safety and Efficacy of Orphan Nano Drugs to Treat High Cholesterol and Related Conditions and to Prevent Cardiovascular Disease under Synchrotron Radiation", J Pharm Sci Emerg Drugs 5: 1, 2017.

[178] A. Heidari, "Non-Linear Compact Proton Synchrotrons to Improve Human Cancer Cells and Tissues Treatments and Diagnostics through Particle Therapy Accelerators with Monochromatic Microbeams", J Cell Biol Mol Sci 2 (1): 1-5, 2017.

[179] A. Heidari, "Design of Targeted Metal Chelation Therapeutics Nanocapsules as Colloidal Carriers and Blood-Brain Barrier (BBB) Translocation to Targeted Deliver Anti-Cancer Nano Drugs into the Human Brain to Treat Alzheimer's Disease under Synchrotron Radiation", J Nanotechnol Material Sci 4 (2): 1-5, 2017

[180] R. Gobato, A. Heidari, "Calculations Using Quantum Chemistry for Inorganic Molecule Simulation BeLi $i_{2} \mathrm{SeSi}$, Science Journal of Analytical Chemistry, Vol. 5, No. 6, Pages 76-85, 2017.

[181] A. Heidari, "Different High-Resolution Simulations of Medical, Medicinal, Clinical, Pharmaceutical and Therapeutics Oncology of Human Lung Cancer Translational Anti-Cancer Nano Drugs Delivery Treatment Process under Synchrotron and X-Ray Radiations", J Med Oncol. Vol. 1 No. 1: 1, 2017.

[182] A. Heidari, "A Modern Ethnomedicinal Technique for Transformation, Prevention and Treatment of Human Malignant Gliomas Tumors into Human Benign Gliomas Tumors under Synchrotron Radiation", Am J Ethnomed, Vol. 4 No. 1: 10, 2017.

[183] A. Heidari, "Active Targeted Nanoparticles for Anti-Cancer Nano Drugs Delivery across the Blood-Brain Barrier for 
Human Brain Cancer Treatment, Multiple Sclerosis (MS) and Alzheimer's Diseases Using Chemical Modifications of AntiCancer Nano Drugs or Drug-Nanoparticles through Zika Virus (ZIKV) Nanocarriers under Synchrotron Radiation", J Med Chem Toxicol, 2 (3): 1-5, 2017.

[184] A. Heidari, "Investigation of Medical, Medicinal, Clinical and Pharmaceutical Applications of Estradiol, Mestranol (Norlutin), Norethindrone (NET), Norethisterone Acetate (NETA), Norethisterone Enanthate (NETE) and Testosterone Nanoparticles as Biological Imaging, Cell Labeling, AntiMicrobial Agents and Anti-Cancer Nano Drugs in Nanomedicines Based Drug Delivery Systems for AntiCancer Targeting and Treatment", Parana Journal of Science and Education (PJSE)-v.3, n.4, (10-19) October 12, 2017.

[185] A. Heidari, "A Comparative Computational and Experimental Study on Different Vibrational Biospectroscopy Methods, Techniques and Applications for Human Cancer Cells in Tumor Tissues Simulation, Modeling, Research, Diagnosis and Treatment", Open J Anal Bioanal Chem 1 (1): 014-020, 2017.

[186] A. Heidari, "Combination of DNA/RNA Ligands and Linear/Non-Linear Visible-Synchrotron Radiation-Driven NDoped Ordered Mesoporous Cadmium Oxide (CdO) Nanoparticles Photocatalysts Channels Resulted in an Interesting Synergistic Effect Enhancing Catalytic AntiCancer Activity", Enz Eng 6: 1, 2017.

[187] A. Heidari, "Modern Approaches in Designing Ferritin, Ferritin Light Chain, Transferrin, Beta-2 Transferrin and Bacterioferritin-Based Anti-Cancer Nano Drugs Encapsulating Nanosphere as DNA-Binding Proteins from Starved Cells (DPS)", Mod Appro Drug Des. 1 (1). MADD.000504. 2017.

[188] A. Heidari, "Potency of Human Interferon $\beta-1 \mathrm{a}$ and Human Interferon $\beta-1 \mathrm{~b}$ in Enzymotherapy, Immunotherapy, Chemotherapy, Radiotherapy, Hormone Therapy and Targeted Therapy of Encephalomyelitis Disseminate/Multiple Sclerosis (MS) and Hepatitis A, B, C, D, E, F and G Virus Enter and Targets Liver Cells", J Proteomics Enzymol 6: 1, 2017.

[189] A. Heidari, "Transport Therapeutic Active Targeting of Human Brain Tumors Enable Anti-Cancer Nanodrugs Delivery across the Blood-Brain Barrier (BBB) to Treat Brain Diseases Using Nanoparticles and Nanocarriers under Synchrotron Radiation", J Pharm Pharmaceutics 4 (2): 1-5, 2017.

[190] A. Heidari, C. Brown, "Combinatorial Therapeutic Approaches to DNA/RNA and Benzylpenicillin (Penicillin G), Fluoxetine Hydrochloride (Prozac and Sarafem), Propofol (Diprivan), Acetylsalicylic Acid (ASA) (Aspirin), Naproxen Sodium (Aleve and Naprosyn) and Dextromethamphetamine Nanocapsules with Surface Conjugated DNA/RNA to Targeted Nano Drugs for Enhanced Anti-Cancer Efficacy and Targeted Cancer Therapy Using Nano Drugs Delivery Systems", Ann Adv Chem. 1 (2): 061-069, 2017.

[191] A. Heidari, "High-Resolution Simulations of Human Brain Cancer Translational Nano Drugs Delivery Treatment Process under Synchrotron Radiation", J Transl Res. 1 (1): 1-3, 2017.

[192] A. Heidari, 'Investigation of Anti-Cancer Nano Drugs' Effects' Trend on Human Pancreas Cancer Cells and Tissues Prevention, Diagnosis and Treatment Process under Synchrotron and X-Ray Radiations with the Passage of Time Using Mathematica", Current Trends Anal Bioanal Chem, 1 (1): 36-41, 2017.

[193] A. Heidari, "Pros and Cons Controversy on Molecular Imaging and Dynamics of Double-Standard DNA/RNA of Human Preserving Stem Cells-Binding Nano Molecules with Androgens/Anabolic Steroids (AAS) or Testosterone Derivatives through Tracking of Helium-4 Nucleus (Alpha Particle) Using Synchrotron Radiation", Arch Biotechnol Biomed. 1 (1): 067-0100, 2017.
[194] A. Heidari, "Visualizing Metabolic Changes in Probing Human Cancer Cells and Tissues Metabolism Using Vivo ${ }^{1} \mathrm{H}$ or Proton NMR, ${ }^{13} \mathrm{C}$ NMR, ${ }^{15} \mathrm{~N}$ NMR and ${ }^{31} \mathrm{P}$ NMR Spectroscopy and Self-Organizing Maps under Synchrotron Radiation", SOJ Mater Sci Eng 5 (2): 1-6, 2017.

[195] A. Heidari, "Cavity Ring-Down Spectroscopy (CRDS), Circular Dichroism Spectroscopy, Cold Vapour Atomic Fluorescence Spectroscopy and Correlation Spectroscopy Comparative Study on Malignant and Benign Human Cancer Cells and Tissues with the Passage of Time under Synchrotron Radiation", Enliven: Challenges Cancer Detect Ther 4 (2): e001, 2017.

[196] A. Heidari, "Laser Spectroscopy, Laser-Induced Breakdown Spectroscopy and Laser-Induced Plasma Spectroscopy Comparative Study on Malignant and Benign Human Cancer Cells and Tissues with the Passage of Time under Synchrotron Radiation", Int J Hepatol Gastroenterol, 3 (4): 079-084, 2017.

[197] A. Heidari, "Time-Resolved Spectroscopy and Time-Stretch Spectroscopy Comparative Study on Malignant and Benign Human Cancer Cells and Tissues with the Passage of Time under Synchrotron Radiation", Enliven: Pharmacovigilance and Drug Safety 4 (2): e001, 2017.

[198] A. Heidari, "Overview of the Role of Vitamins in Reducing Negative Effect of Decapeptyl (Triptorelin Acetate or Pamoate Salts) on Prostate Cancer Cells and Tissues in Prostate Cancer Treatment Process through Transformation of Malignant Prostate Tumors into Benign Prostate Tumors under Synchrotron Radiation", Open J Anal Bioanal Chem 1 (1): 021-026, 2017.

[199] A. Heidari, "Electron Phenomenological Spectroscopy, Electron Paramagnetic Resonance (EPR) Spectroscopy and Electron Spin Resonance (ESR) Spectroscopy Comparative Study on Malignant and Benign Human Cancer Cells and Tissues with the Passage of Time under Synchrotron Radiation", Austin J Anal Pharm Chem. 4 (3): 1091, 2017.

[200] A. Heidari, "Therapeutic Nanomedicine Different HighResolution Experimental Images and Computational Simulations for Human Brain Cancer Cells and Tissues Using Nanocarriers Deliver DNA/RNA to Brain Tumors under Synchrotron Radiation with the Passage of Time Using Mathematica and MATLAB", Madridge J Nano Tech. Sci. 2 (2): 77-83, 2017.

[201] A. Heidari, "A Consensus and Prospective Study on Restoring Cadmium Oxide (CdO) Nanoparticles Sensitivity in Recurrent Ovarian Cancer by Extending the Cadmium Oxide (CdO) Nanoparticles-Free Interval Using Synchrotron Radiation Therapy as Antibody-Drug Conjugate for the Treatment of Limited-Stage Small Cell Diverse Epithelial Cancers", Cancer Clin Res Rep, 1: 2, e001, 2017.

[202] A. Heidari, "A Novel and Modern Experimental Imaging and Spectroscopy Comparative Study on Malignant and Benign Human Cancer Cells and Tissues with the Passage of Time under White Synchrotron Radiation", Cancer Sci Res Open Access 4 (2): 1-8, 2017.

[203] A. Heidari, "Different High-Resolution Simulations of Medical, Medicinal, Clinical, Pharmaceutical and Therapeutics Oncology of Human Breast Cancer Translational Nano Drugs Delivery Treatment Process under Synchrotron and X-Ray Radiations", J Oral Cancer Res 1 (1): 12-17, 2017.

[204] A. Heidari, "Vibrational Decihertz $(\mathrm{dHz})$, Centihertz $(\mathrm{cHz})$, Millihertz $(\mathrm{mHz})$, Microhertz $(\mu \mathrm{Hz})$, Nanohertz $(\mathrm{nHz})$, Picohertz (pHz), Femtohertz (fHz), Attohertz $(\mathrm{aHz})$, Zeptohertz $(\mathrm{zHz})$ and Yoctohertz $(\mathrm{yHz})$ Imaging and Spectroscopy Comparative Study on Malignant and Benign Human Cancer Cells and Tissues under Synchrotron Radiation", International Journal of Biomedicine, 7 (4), 335340, 2017. 
[205] A. Heidari, "Force Spectroscopy and Fluorescence Spectroscopy Comparative Study on Malignant and Benign Human Cancer Cells and Tissues with the Passage of Time under Synchrotron Radiation", EC Cancer, 2 (5), 239-246, 2017.

[206] A. Heidari, "Photoacoustic Spectroscopy, Photoemission Spectroscopy and Photothermal Spectroscopy Comparative Study on Malignant and Benign Human Cancer Cells and Tissues with the Passage of Time under Synchrotron Radiation", BAOJ Cancer Res Ther, 3: 3, 045-052, 2017.

[207] A. Heidari, "J-Spectroscopy, Exchange Spectroscopy (EXSY), Nuclear Overhauser Effect Spectroscopy (NOESY) and Total Correlation Spectroscopy (TOCSY) Comparative Study on Malignant and Benign Human Cancer Cells and Tissues under Synchrotron Radiation", EMS Eng Sci J, 1 (2): 006-013, 2017.

[208] A. Heidari, "Neutron Spin Echo Spectroscopy and Spin Noise Spectroscopy Comparative Study on Malignant and Benign Human Cancer Cells and Tissues with the Passage of Time under Synchrotron Radiation", Int J Biopharm Sci, 1: 103107, 2017.

[209] A. Heidari, "Vibrational Decahertz (daHz), Hectohertz $(\mathrm{hHz})$, Kilohertz (kHz), Megahertz (MHz), Gigahertz (GHz), Terahertz (THz), Petahertz (PHz), Exahertz (EHz), Zettahertz $(\mathrm{ZHz})$ and Yottahertz $(\mathrm{YHz})$ Imaging and Spectroscopy Comparative Study on Malignant and Benign Human Cancer Cells and Tissues under Synchrotron Radiation", Madridge $J$ Anal Sci Instrum, 2 (1): 41-46, 2017.

[210] A. Heidari, "Two-Dimensional Infrared Correlation Spectroscopy, Linear Two-Dimensional Infrared Spectroscopy and Non-Linear Two-Dimensional Infrared Spectroscopy Comparative Study on Malignant and Benign Human Cancer Cells and Tissues under Synchrotron Radiation with the Passage of Time", J Mater Sci Nanotechnol 6 (1): 101, 2018.

[211] A. Heidari, "Fourier Transform Infrared (FTIR) Spectroscopy, Near-Infrared Spectroscopy (NIRS) and Mid-Infrared Spectroscopy (MIRS) Comparative Study on Malignant and Benign Human Cancer Cells and Tissues under Synchrotron Radiation with the Passage of Time", Int J Nanotechnol Nanomed, Volume 3, Issue 1, Pages 1-6, 2018.

[212] A. Heidari, "Infrared Photo Dissociation Spectroscopy and Infrared Correlation Table Spectroscopy Comparative Study on Malignant and Benign Human Cancer Cells and Tissues under Synchrotron Radiation with the Passage of Time", Austin Pharmacol Pharm, 3 (1): 1011, 2018.

[213] A. Heidari, "Novel and Transcendental Prevention, Diagnosis and Treatment Strategies for Investigation of Interaction among Human Blood Cancer Cells, Tissues, Tumors and Metastases with Synchrotron Radiation under Anti-Cancer Nano Drugs Delivery Efficacy Using MATLAB Modeling and Simulation", Madridge J Nov Drug Res, 1 (1): 18-24, 2017.

[214] A. Heidari, "Comparative Study on Malignant and Benign Human Cancer Cells and Tissues with the Passage of Time under Synchrotron Radiation", Open Access J Trans Med Res, 2 (1): 00026-00032, 2018.

[215] M. R. R. Gobato, R. Gobato, A. Heidari, "Planting of Jaboticaba Trees for Landscape Repair of Degraded Area", Landscape Architecture and Regional Planning, Vol. 3, No. 1, 2018, Pages 1-9, 2018.

[216] A. Heidari, "Fluorescence Spectroscopy, Phosphorescence Spectroscopy and Luminescence Spectroscopy Comparative Study on Malignant and Benign Human Cancer Cells and Tissues under Synchrotron Radiation with the Passage of Time", SM J Clin. Med. Imaging, 4 (1): 1018, 2018.

[217] A. Heidari, "Nuclear Inelastic Scattering Spectroscopy (NISS) and Nuclear Inelastic Absorption Spectroscopy (NIAS) Comparative Study on Malignant and Benign Human Cancer Cells and Tissues under Synchrotron Radiation", Int J Pharm Sci, 2 (1): 1-14, 2018.
[218] A. Heidari, "X-Ray Diffraction (XRD), Powder X-Ray Diffraction (PXRD) and Energy-Dispersive $X-$ Ray Diffraction (EDXRD) Comparative Study on Malignant and Benign Human Cancer Cells and Tissues under Synchrotron Radiation", J Oncol Res; 2 (1): 1-14, 2018.

[219] A. Heidari, "Correlation Two-Dimensional Nuclear Magnetic Resonance (NMR) (2D-NMR) (COSY) Imaging and Spectroscopy Comparative Study on Malignant and Benign Human Cancer Cells and Tissues under Synchrotron Radiation", EMS Can Sci, 1-1-001, 2018.

[220] A. Heidari, "Thermal Spectroscopy, Photothermal Spectroscopy, Thermal Microspectroscopy, Photothermal Microspectroscopy, Thermal Macrospectroscopy and Photothermal Macrospectroscopy Comparative Study on Malignant and Benign Human Cancer Cells and Tissues with the Passage of Time under Synchrotron Radiation", SM J Biometrics Biostat, 3 (1): 1024, 2018.

[221] A. Heidari, "A Modern and Comprehensive Experimental Biospectroscopic Comparative Study on Human Common Cancers' Cells, Tissues and Tumors before and after Synchrotron Radiation Therapy", Open Acc J Oncol Med. 1 (1), 2018.

[222] A. Heidari, "Heteronuclear Correlation Experiments such as Heteronuclear Single-Quantum Correlation Spectroscopy (HSQC), Heteronuclear Multiple-Quantum Correlation Spectroscopy (HMQC) and Heteronuclear Multiple-Bond Correlation Spectroscopy (HMBC) Comparative Study on Malignant and Benign Human Endocrinology and Thyroid Cancer Cells and Tissues under Synchrotron Radiation", J Endocrinol Thyroid Res, 3 (1): 555603, 2018.

[223] A. Heidari, "Nuclear Resonance Vibrational Spectroscopy (NRVS), Nuclear Inelastic Scattering Spectroscopy (NISS), Nuclear Inelastic Absorption Spectroscopy (NIAS) and Nuclear Resonant Inelastic X-Ray Scattering Spectroscopy (NRIXSS) Comparative Study on Malignant and Benign Human Cancer Cells and Tissues under Synchrotron Radiation”, Int J Bioorg Chem Mol Biol. 6 (1e): 1-5, 2018.

[224] A. Heidari, "A Novel and Modern Experimental Approach to Vibrational Circular Dichroism Spectroscopy and Video Spectroscopy Comparative Study on Malignant and Benign Human Cancer Cells and Tissues with the Passage of Time under White and Monochromatic Synchrotron Radiation", Glob J Endocrinol Metab. 1 (3). GJEM. 000514-000519, 2018.

[225] A. Heidari, "Pros and Cons Controversy on Heteronuclear Correlation Experiments such as Heteronuclear SingleQuantum Correlation Spectroscopy (HSQC), Heteronuclear Multiple-Quantum Correlation Spectroscopy (HMQC) and Heteronuclear Multiple-Bond Correlation Spectroscopy (HMBC) Comparative Study on Malignant and Benign Human Cancer Cells and Tissues under Synchrotron Radiation", EMS Pharma J. 1 (1): 002-008, 2018.

[226] A. Heidari, "A Modern Comparative and Comprehensive Experimental Biospectroscopic Study on Different Types of Infrared Spectroscopy of Malignant and Benign Human Cancer Cells and Tissues with the Passage of Time under Synchrotron Radiation", J Analyt Molecul Tech. 3 (1): 8, 2018.

[227] A. Heidari, "Investigation of Cancer Types Using Synchrotron Technology for Proton Beam Therapy: An Experimental Biospectroscopic Comparative Study", European Modern Studies Journal, Vol. 2, No. 1, 13-29, 2018.

[228] A. Heidari, "Saturated Spectroscopy and Unsaturated Spectroscopy Comparative Study on Malignant and Benign Human Cancer Cells and Tissues with the Passage of Time under Synchrotron Radiation", Imaging J Clin Medical Sci. 5 (1): 001-007, 2018.

[229] A. Heidari, "Small-Angle Neutron Scattering (SANS) and Wide-Angle X-Ray Diffraction (WAXD) Comparative Study on Malignant and Benign Human Cancer Cells and Tissues 
under Synchrotron Radiation", Int J Bioorg Chem Mol Biol. 6 (2e): 1-6, 2018.

[230] A. Heidari, "Investigation of Bladder Cancer, Breast Cancer, Colorectal Cancer, Endometrial Cancer, Kidney Cancer, Leukemia, Liver, Lung Cancer, Melanoma, Non-Hodgkin Lymphoma, Pancreatic Cancer, Prostate Cancer, Thyroid Cancer and Non-Melanoma Skin Cancer Using Synchrotron Technology for Proton Beam Therapy: An Experimental Biospectroscopic Comparative Study", Ther Res Skin Dis 1 (1), 2018.

[231] A. Heidari, "Attenuated Total Reflectance Fourier Transform Infrared (ATR-FTIR) Spectroscopy, Micro-Attenuated Total Reflectance Fourier Transform Infrared (Micro-ATR-FTIR) Spectroscopy and Macro-Attenuated Total Reflectance Fourier Transform Infrared (Macro-ATR-FTIR) Spectroscopy Comparative Study on Malignant and Benign Human Cancer Cells and Tissues under Synchrotron Radiation with the Passage of Time", International Journal of Chemistry Papers, 2 (1): 1-12, 2018.

[232] A. Heidari, "Mössbauer Spectroscopy, Mössbauer Emission Spectroscopy and ${ }^{57} \mathrm{Fe}$ Mössbauer Spectroscopy Comparative Study on Malignant and Benign Human Cancer Cells and Tissues under Synchrotron Radiation", Acta Scientific Cancer Biology 2.3: 17-20, 2018.

[233] A. Heidari, "Comparative Study on Malignant and Benign Human Cancer Cells and Tissues under Synchrotron Radiation with the Passage of Time", Organic \& Medicinal Chem IJ. 6 (1): 555676, 2018.

[234] A. Heidari, "Correlation Spectroscopy, Exclusive Correlation Spectroscopy and Total Correlation Spectroscopy Comparative Study on Malignant and Benign Human AIDSRelated Cancers Cells and Tissues with the Passage of Time under Synchrotron Radiation", Int J Bioanal Biomed. 2 (1): 001-007, 2018.

[235] A. Heidari, "Biomedical Instrumentation and Applications of Biospectroscopic Methods and Techniques in Malignant and Benign Human Cancer Cells and Tissues Studies under Synchrotron Radiation and Anti-Cancer Nano Drugs Delivery", Am J Nanotechnol Nanomed. 1 (1): 001-009, 2018.

[236] A. Heidari, "Vivo ${ }^{1} \mathrm{H}$ or Proton NMR, ${ }^{13} \mathrm{C}$ NMR, ${ }^{15} \mathrm{~N}$ NMR and ${ }^{31} \mathrm{P}$ NMR Spectroscopy Comparative Study on Malignant and Benign Human Cancer Cells and Tissues under Synchrotron Radiation", Ann Biomet Biostat. 1 (1): 1001, 2018.

[237] A. Heidari, "Grazing-Incidence Small-Angle Neutron Scattering (GISANS) and Grazing-Incidence X-Ray Diffraction (GIXD) Comparative Study on Malignant and Benign Human Cancer Cells, Tissues and Tumors under Synchrotron Radiation", Ann Cardiovasc Surg. 1 (2): 1006, 2018.

[238] A. Heidari, "Adsorption Isotherms and Kinetics of MultiWalled Carbon Nanotubes (MWCNTs), Boron Nitride Nanotubes (BNNTs), Amorphous Boron Nitride Nanotubes (a-BNNTs) and Hexagonal Boron Nitride Nanotubes (hBNNTs) for Eliminating Carcinoma, Sarcoma, Lymphoma, Leukemia, Germ Cell Tumor and Blastoma Cancer Cells and Tissues", Clin Med Rev Case Rep 5: 201, 2018.

[239] A. Heidari, "Correlation Spectroscopy (COSY), Exclusive Correlation Spectroscopy (ECOSY), Total Correlation Spectroscopy (TOCSY), Incredible Natural-Abundance Double-Quantum Transfer Experiment (INADEQUATE), Heteronuclear Single-Quantum Correlation Spectroscopy (HSQC), Heteronuclear Multiple-Bond Correlation Spectroscopy (HMBC), Nuclear Overhauser Effect Spectroscopy (NOESY) and Rotating Frame Nuclear Overhauser Effect Spectroscopy (ROESY) Comparative Study on Malignant and Benign Human Cancer Cells and Tissues under Synchrotron Radiation", Acta Scientific Pharmaceutical Sciences 2.5: 30-35, 2018.
[240] A. Heidari, "Small-Angle X-Ray Scattering (SAXS), UltraSmall Angle $X-$ Ray Scattering (USAXS), Fluctuation X-Ray Scattering (FXS), Wide-Angle X-Ray Scattering (WAXS), Grazing-Incidence Small-Angle X-Ray Scattering (GISAXS), Grazing-Incidence Wide-Angle X-Ray Scattering (GIWAXS), Small-Angle Neutron Scattering (SANS), Grazing-Incidence Small-Angle Neutron Scattering (GISANS), X-Ray Diffraction (XRD), Powder X-Ray Diffraction (PXRD), Wide-Angle X-Ray Diffraction (WAXD), Grazing-Incidence X-Ray Diffraction (GIXD) and EnergyDispersive X-Ray Diffraction (EDXRD) Comparative Study on Malignant and Benign Human Cancer Cells and Tissues under Synchrotron Radiation", Oncol Res Rev, Volume 1 (1): 1-10, 2018

[241] A. Heidari, "Pump-Probe Spectroscopy and Transient Grating Spectroscopy Comparative Study on Malignant and Benign Human Cancer Cells and Tissues with the Passage of Time under Synchrotron Radiation", Adv Material Sci Engg, Volume 2, Issue 1, Pages 1-7, 2018.

[242] A. Heidari, "Grazing-Incidence Small-Angle X-Ray Scattering (GISAXS) and Grazing-Incidence Wide-Angle XRay Scattering (GIWAXS) Comparative Study on Malignant and Benign Human Cancer Cells and Tissues under Synchrotron Radiation", Insights Pharmacol Pharm Sci 1 (1): 1-8, 2018.

[243] A. Heidari, "Acoustic Spectroscopy, Acoustic Resonance Spectroscopy and Auger Spectroscopy Comparative Study on Anti-Cancer Nano Drugs Delivery in Malignant and Benign Human Cancer Cells and Tissues with the Passage of Time under Synchrotron Radiation", Nanosci Technol 5 (1): 1-9, 2018.

[244] A. Heidari, "Niobium, Technetium, Ruthenium, Rhodium, Hafnium, Rhenium, Osmium and Iridium Ions Incorporation into the Nano Polymeric Matrix (NPM) by Immersion of the Nano Polymeric Modified Electrode (NPME) as Molecular Enzymes and Drug Targets for Human Cancer Cells, Tissues and Tumors Treatment under Synchrotron and Synchrocyclotron Radiations", Nanomed Nanotechnol, 3 (2): 000138, 2018.

[245] A. Heidari, "Homonuclear Correlation Experiments such as Homonuclear Single-Quantum Correlation Spectroscopy (HSQC), Homonuclear Multiple-Quantum Correlation Spectroscopy (HMQC) and Homonuclear Multiple-Bond Correlation Spectroscopy (HMBC) Comparative Study on Malignant and Benign Human Cancer Cells and Tissues under Synchrotron Radiation", Austin J Proteomics Bioinform \& Genomics. 5 (1): 1024, 2018.

[246] A. Heidari, "Atomic Force Microscopy Based Infrared (AFMIR) Spectroscopy and Nuclear Resonance Vibrational Spectroscopy Comparative Study on Malignant and Benign Human Cancer Cells and Tissues under Synchrotron Radiation with the Passage of Time", J Appl Biotechnol Bioeng. 5 (3): 142-148, 2018.

[247] A. Heidari, "Time-Dependent Vibrational Spectral Analysis of Malignant and Benign Human Cancer Cells and Tissues under Synchrotron Radiation", J Cancer Oncol, 2 (2): 000124, 2018.

[248] A. Heidari, "Palauamine and Olympiadane Nano Molecules Incorporation into the Nano Polymeric Matrix (NPM) by Immersion of the Nano Polymeric Modified Electrode (NPME) as Molecular Enzymes and Drug Targets for Human Cancer Cells, Tissues and Tumors Treatment under Synchrotron and Synchrocyclotron Radiations", Arc Org Inorg Chem Sci 3 (1), 2018.

[249] R. Gobato, A. Heidari, "Infrared Spectrum and Sites of Action of Sanguinarine by Molecular Mechanics and ab initio Methods", International Journal of Atmospheric and Oceanic Sciences. Vol. 2, No. 1, pp. 1-9, 2018.

[250] A. Heidari, "Angelic Acid, Diabolic Acids, Draculin and Miraculin Nano Molecules Incorporation into the Nano Polymeric Matrix (NPM) by Immersion of the Nano Polymeric 
Modified Electrode (NPME) as Molecular Enzymes and Drug Targets for Human Cancer Cells, Tissues and Tumors Treatment Under Synchrotron and Synchrocyclotron Radiations", Med \& Analy Chem Int J, 2 (1): 000111, 2018.

[251] A. Heidari, "Gamma Linolenic Methyl Ester, 5-Heptadeca5,8,11-Trienyl 1,3,4-Oxadiazole-2-Thiol, Sulphoquinovosyl Diacyl Glycerol, Ruscogenin, Nocturnoside B, Protodioscine B, Parquisoside-B, Leiocarposide, Narangenin, 7-Methoxy Hespertin, Lupeol, Rosemariquinone, Rosmanol and Rosemadiol Nano Molecules Incorporation into the Nano Polymeric Matrix (NPM) by Immersion of the Nano Polymeric Modified Electrode (NPME) as Molecular Enzymes and Drug Targets for Human Cancer Cells, Tissues and Tumors Treatment under Synchrotron and Synchrocyclotron Radiations", Int J Pharma Anal Acta, 2 (1): 007-014, 2018.

[252] A. Heidari, "Fourier Transform Infrared (FTIR) Spectroscopy, Attenuated Total Reflectance Fourier Transform Infrared (ATR-FTIR) Spectroscopy, Micro-Attenuated Total Reflectance Fourier Transform Infrared (Micro-ATR-FTIR) Spectroscopy, Macro-Attenuated Total Reflectance Fourier Transform Infrared (Macro-ATR-FTIR) Spectroscopy, TwoDimensional Infrared Correlation Spectroscopy, Linear TwoDimensional Infrared Spectroscopy, Non-Linear TwoDimensional Infrared Spectroscopy, Atomic Force Microscopy Based Infrared (AFM-IR) Spectroscopy, Infrared Photodissociation Spectroscopy, Infrared Correlation Table Spectroscopy, Near-Infrared Spectroscopy (NIRS), MidInfrared Spectroscopy (MIRS), Nuclear Resonance Vibrational Spectroscopy, Thermal Infrared Spectroscopy and Photothermal Infrared Spectroscopy Comparative Study on Malignant and Benign Human Cancer Cells and Tissues under Synchrotron Radiation with the Passage of Time", Glob Imaging Insights, Volume 3 (2): 1-14, 2018.

[253] A. Heidari, "Heteronuclear Single-Quantum Correlation Spectroscopy (HSQC) and Heteronuclear Multiple-Bond Correlation Spectroscopy (HMBC) Comparative Study on Malignant and Benign Human Cancer Cells, Tissues and Tumors under Synchrotron and Synchrocyclotron Radiations", Chronicle of Medicine and Surgery 2.3: 144156, 2018.

[254] A. Heidari, "Tetrakis [3, 5-bis (Trifluoromethyl) Phenyl] Borate (BARF)-Enhanced Precatalyst Preparation Stabilization and Initiation (EPPSI) Nano Molecules", Medical Research and Clinical Case Reports 2.1: 113-126, 2018.

[255] A. Heidari, "Sydnone, Münchnone, Montréalone, Mogone, Montelukast, Quebecol and Palau'amine-Enhanced Precatalyst Preparation Stabilization and Initiation (EPPSI) Nano Molecules", Sur Cas Stud Op Acc J. 1 (3), 2018.

[256] A. Heidari, "Fornacite, Orotic Acid, Rhamnetin, Sodium Ethyl Xanthate (SEX) and Spermine (Spermidine or Polyamine) Nanomolecules Incorporation into the Nanopolymeric Matrix (NPM)", International Journal of Biochemistry and Biomolecules, Vol. 4: Issue 1, Pages 1-19, 2018.

[257] A. Heidari, R. Gobato, "Putrescine, Cadaverine, Spermine and Spermidine-Enhanced Precatalyst Preparation Stabilization and Initiation (EPPSI) Nano Molecules", Parana Journal of Science and Education (PJSE)-v.4, n.5, (1-14) July 1, 2018.

[258] A. Heidari, "Cadaverine (1,5-Pentanediamine or Pentamethylenediamine), Diethyl Azodicarboxylate (DEAD or DEADCAT) and Putrescine (Tetramethylenediamine) Nano Molecules Incorporation into the Nano Polymeric Matrix (NPM) by Immersion of the Nano Polymeric Modified Electrode (NPME) as Molecular Enzymes and Drug Targets for Human Cancer Cells, Tissues and Tumors Treatment under Synchrotron and Synchrocyclotron Radiations", Hiv and Sexual Health Open Access Open Journal. 1 (1): 4-11, 2018.

[259] A. Heidari, "Improving the Performance of NanoEndofullerenes in Polyaniline Nanostructure-Based Biosensors by Covering Californium Colloidal Nanoparticles with Multi-Walled Carbon Nanotubes", Journal of Advances in Nanomaterials, Vol. 3, No. 1, Pages 1-28, 2018.

[260] R. Gobato, A. Heidari, "Molecular Mechanics and Quantum Chemical Study on Sites of Action of Sanguinarine Using Vibrational Spectroscopy Based on Molecular Mechanics and Quantum Chemical Calculations", Malaysian Journal of Chemistry, Vol. 20 (1), 1-23, 2018.

[261] A. Heidari, "Vibrational Biospectroscopic Studies on Anticancer Nanopharmaceuticals (Part I)", Malaysian Journal of Chemistry, Vol. 20 (1), 33-73, 2018.

[262] A. Heidari, "Vibrational Biospectroscopic Studies on Anticancer Nanopharmaceuticals (Part II)", Malaysian Journal of Chemistry, Vol. 20 (1), 74-117, 2018.

[263] A. Heidari, "Uranocene $\left(\mathrm{U}\left(\mathrm{C}_{8} \mathrm{H}_{8}\right)_{2}\right)$ and Bis(Cyclooctatetraene)Iron $\quad\left(\mathrm{Fe}\left(\mathrm{C}_{8} \mathrm{H}_{8}\right)_{2}\right.$ or $\left.\mathrm{Fe}(\mathrm{COT})_{2}\right)-$ Enhanced Precatalyst Preparation Stabilization and Initiation (EPPSI) Nano Molecules", Chemistry Reports, Vol. 1, Iss. 2, Pages 1-16, 2018.

[264] A. Heidari, "Biomedical Systematic and Emerging Technological Study on Human Malignant and Benign Cancer Cells and Tissues Biospectroscopic Analysis under Synchrotron Radiation", Glob Imaging Insights, Volume 3 (3): 1-7, 2018.

[265] A. Heidari, "Deep-Level Transient Spectroscopy and X-Ray Photoelectron Spectroscopy (XPS) Comparative Study on Malignant and Benign Human Cancer Cells and Tissues with the Passage of Time under Synchrotron Radiation", Res Dev Material Sci. 7(2). RDMS.000659, 2018.

[266] A. Heidari, "C70-Carboxyfullerenes Nano Molecules Incorporation into the Nano Polymeric Matrix (NPM) by Immersion of the Nano Polymeric Modified Electrode (NPME) as Molecular Enzymes and Drug Targets for Human Cancer Cells, Tissues and Tumors Treatment under Synchrotron and Synchrocyclotron Radiations", Glob Imaging Insights, Volume 3 (3): 1-7, 2018.

[267] A. Heidari, "The Effect of Temperature on Cadmium Oxide (CdO) Nanoparticles Produced by Synchrotron Radiation in the Human Cancer Cells, Tissues and Tumors", International Journal of Advanced Chemistry, 6 (2) 140-156, 2018.

[268] A. Heidari, "A Clinical and Molecular Pathology Investigation of Correlation Spectroscopy (COSY), Exclusive Correlation Spectroscopy (ECOSY), Total Correlation Spectroscopy (TOCSY), Heteronuclear Single-Quantum Correlation Spectroscopy (HSQC) and Heteronuclear Multiple-Bond Correlation Spectroscopy (HMBC) Comparative Study on Malignant and Benign Human Cancer Cells, Tissues and Tumors under Synchrotron and Synchrocyclotron Radiations Using Cyclotron versus Synchrotron, Synchrocyclotron and the Large Hadron Collider (LHC) for Delivery of Proton and Helium Ion (Charged Particle) Beams for Oncology Radiotherapy", European Journal of Advances in Engineering and Technology, 5 (7): 414-426, 2018.

[269] A. Heidari, "Nano Molecules Incorporation into the Nano Polymeric Matrix (NPM) by Immersion of the Nano Polymeric Modified Electrode (NPME) as Molecular Enzymes and Drug Targets for Human Cancer Cells, Tissues and Tumors Treatment under Synchrotron and Synchrocyclotron Radiations", J Oncol Res; 1 (1): 1-20, 2018.

[270] A. Heidari, "Use of Molecular Enzymes in the Treatment of Chronic Disorders", Canc Oncol Open Access J. 1 (1): 1215, 2018.

[271] A. Heidari, "Vibrational Biospectroscopic Study and Chemical Structure Analysis of Unsaturated Polyamides Nanoparticles as Anti-Cancer Polymeric Nanomedicines Using Synchrotron Radiation", International Journal of Advanced Chemistry, 6 (2), 167-189, 2018.

[272] A. Heidari, "Adamantane, Irene, Naftazone and PyridineEnhanced Precatalyst Preparation Stabilization and Initiation (PEPPSI) Nano Molecules", Madridge J Nov Drug Res. 2 (1): 61-67, 2018. 
[273] A. Heidari, "Heteronuclear Single-Quantum Correlation Spectroscopy (HSQC) and Heteronuclear Multiple-Bond Correlation Spectroscopy (HMBC) Comparative Study on Malignant and Benign Human Cancer Cells and Tissues with the Passage of Time under Synchrotron Radiation", Madridge J Nov Drug Res, 2 (1): 68-74, 2018.

[274] A. Heidari, R. Gobato, "A Novel Approach to Reduce Toxicities and to Improve Bioavailabilities of DNA/RNA of Human Cancer Cells-Containing Cocaine (Coke), Lysergide (Lysergic Acid Diethyl Amide or LSD), $\Delta^{9}$ Tetrahydrocannabinol (THC) [(-)-trans- $\Delta^{9}-$ Tetrahydrocannabinol], Theobromine (Xantheose), Caffeine, Aspartame (APM) (NutraSweet) and Zidovudine (ZDV) [Azidothymidine (AZT)] as Anti-Cancer Nano Drugs by Coassembly of Dual Anti-Cancer Nano Drugs to Inhibit DNA/RNA of Human Cancer Cells Drug Resistance", Parana Journal of Science and Education, v. 4, n. 6, pp. 1-17, 2018.

[275] A. Heidari, R. Gobato, "Ultraviolet Photoelectron Spectroscopy (UPS) and Ultraviolet-Visible (UV-Vis) Spectroscopy Comparative Study on Malignant and Benign Human Cancer Cells and Tissues with the Passage of Time under Synchrotron Radiation", Parana Journal of Science and Education, v. 4, n. 6, pp. 18-33, 2018.

[276] R. Gobato, A. Heidari, A. Mitra, "The Creation of $\mathrm{C}_{13} \mathrm{H}_{20} \mathrm{BeLi}_{2} \mathrm{SeSi}$. The Proposal of a Bio-Inorganic Molecule, Using $A b$ Initio Methods for the Genesis of a Nano Membrane", Arc Org Inorg Chem Sci 3 (4). AOICS.MS.ID.000167, 2018.

[277] R. Gobato, A. Heidari, A. Mitra, "Using the Quantum Chemistry for Genesis of a Nano Biomembrane with a Combination of the Elements $\mathrm{Be}, \mathrm{Li}, \mathrm{Se}, \mathrm{Si}, \mathrm{C}$ and $\mathrm{H}$ ", ResearchGate, See discussions, stats, and author profiles for this publication https://www.researchgate.net/publication/326201181, 2018.

[278] R. Gobato, A. Heidari, "Using the Quantum Chemistry for Genesis of a Nano Biomembrane with a Combination of the Elements $\mathrm{Be}, \mathrm{Li}, \mathrm{Se}, \mathrm{Si}, \mathrm{C}$ and H", J Nanomed Res.7 (4): 241-252, 2018.

[279] A. Heidari, "Bastadins and Bastaranes-Enhanced Precatalyst Preparation Stabilization and Initiation (EPPSI) Nano Molecules", Glob Imaging Insights, Volume 3 (4): 1-7, 2018.

[280] A. Heidari, "Fucitol, Pterodactyladiene, DEAD or DEADCAT (DiEthyl AzoDiCArboxylaTe), Skatole, the NanoPutians, Thebacon, Pikachurin, Tie Fighter, Spermidine and Mirasorvone Nano Molecules Incorporation into the Nano Polymeric Matrix (NPM) by Immersion of the Nano Polymeric Modified Electrode (NPME) as Molecular Enzymes and Drug Targets for Human Cancer Cells, Tissues and Tumors Treatment under Synchrotron and Synchrocyclotron Radiations", Glob Imaging Insights, Volume 3 (4): 1-8, 2018.

[281] E. Dadvar, A. Heidari, "A Review on Separation Techniques of Graphene Oxide (GO)/Base on Hybrid Polymer Membranes for Eradication of Dyes and Oil Compounds: Recent Progress in Graphene Oxide (GO)/Base on Polymer Membranes-Related Nanotechnologies", Clin Med Rev Case Rep 5: 228, 2018.

[282] A. Heidari, R. Gobato, "First-Time Simulation of Deoxyuridine Monophosphate (dUMP) (Deoxyuridylic Acid or Deoxyuridylate) and Vomitoxin (Deoxynivalenol (DON)) $((3 \alpha, 7 \alpha)-3,7,15-$ Trihydroxy-12,13-Epoxytrichothec-9-En8-One)-Enhanced Precatalyst Preparation Stabilization and Initiation (EPPSI) Nano Molecules Incorporation into the Nano Polymeric Matrix (NPM) by Immersion of the Nano Polymeric Modified Electrode (NPME) as Molecular Enzymes and Drug Targets for Human Cancer Cells, Tissues and Tumors Treatment under Synchrotron and Synchrocyclotron Radiations", Parana Journal of Science and Education, Vol. 4, No. 6, pp. 46-67, 2018.

[283] A. Heidari, "Buckminsterfullerene (Fullerene), Bullvalene, Dickite and Josiphos Ligands Nano Molecules Incorporation into the Nano Polymeric Matrix (NPM) by Immersion of the Nano Polymeric Modified Electrode (NPME) as Molecular Enzymes and Drug Targets for Human Hematology and Thromboembolic Diseases Prevention, Diagnosis and Treatment under Synchrotron and Synchrocyclotron Radiations", Glob Imaging Insights, Volume 3 (4): 1-7, 2018.

[284] A. Heidari, "Fluctuation X-Ray Scattering (FXS) and WideAngle X-Ray Scattering (WAXS) Comparative Study on Malignant and Benign Human Cancer Cells and Tissues under Synchrotron Radiation", Glob Imaging Insights, Volume 3 (4): 1-7, 2018.

[285] A. Heidari, "A Novel Approach to Correlation Spectroscopy (COSY), Exclusive Correlation Spectroscopy (ECOSY), Total Correlation Spectroscopy (TOCSY), Incredible NaturalAbundance Double-Quantum Transfer Experiment (INADEQUATE), Heteronuclear Single-Quantum Correlation Spectroscopy (HSQC), Heteronuclear Multiple-Bond Correlation Spectroscopy (HMBC), Nuclear Overhauser Effect Spectroscopy (NOESY) and Rotating Frame Nuclear Overhauser Effect Spectroscopy (ROESY) Comparative Study on Malignant and Benign Human Cancer Cells and Tissues under Synchrotron Radiation", Glob Imaging Insights, Volume 3 (5): 1-9, 2018.

[286] A. Heidari, "Terphenyl-Based Reversible Receptor with Rhodamine, Rhodamine-Based Molecular Probe, Rhodamine-Based Using the Spirolactam Ring Opening, Rhodamine B with Ferrocene Substituent, Calix[4]AreneBased Receptor, Thioether + Aniline-Derived Ligand Framework Linked to a Fluorescein Platform, Mercuryfluor-1 (Flourescent Probe), N,N'-Dibenzyl-1,4,10,13-Tetraraoxa7,16-Diazacyclooctadecane and Terphenyl-Based Reversible Receptor with Pyrene and Quinoline as the Fluorophores-Enhanced Precatalyst Preparation Stabilization and Initiation (EPPSI) Nano Molecules", Glob Imaging Insights, Volume 3 (5): 1-9, 2018.

[287] A. Heidari, "Small-Angle X-Ray Scattering (SAXS), UltraSmall Angle X-Ray Scattering (USAXS), Fluctuation X-Ray Scattering (FXS), Wide-Angle X-Ray Scattering (WAXS), Grazing-Incidence Small-Angle X-Ray Scattering (GISAXS), Grazing-Incidence Wide-Angle X-Ray Scattering (GIWAXS), Small-Angle Neutron Scattering (SANS), Grazing-Incidence Small-Angle Neutron Scattering (GISANS), X-Ray Diffraction (XRD), Powder XRay Diffraction (PXRD), Wide-Angle $X$-Ray Diffraction (WAXD), Grazing-Incidence X-Ray Diffraction (GIXD) and Energy-Dispersive X-Ray Diffraction (EDXRD) Comparative Study on Malignant and Benign Human Cancer Cells and Tissues under Synchrotron Radiation", Glob Imaging Insights, Volume 3 (5): 1-10, 2018.

[288] A. Heidari, "Nuclear Resonant Inelastic X-Ray Scattering Spectroscopy (NRIXSS) and Nuclear Resonance Vibrational Spectroscopy (NRVS) Comparative Study on Malignant and Benign Human Cancer Cells and Tissues under Synchrotron Radiation", Glob Imaging Insights, Volume 3 (5): 1-7, 2018.

[289] A. Heidari, "Small-Angle X-Ray Scattering (SAXS) and Ultra-Small Angle X-Ray Scattering (USAXS) Comparative Study on Malignant and Benign Human Cancer Cells and Tissues under Synchrotron Radiation", Glob Imaging Insights, Volume 3 (5): 1-7, 2018.

[290] A. Heidari, "Curious Chloride $\left(\mathrm{CmCl}_{3}\right)$ and Titanic Chloride $\left(\mathrm{TiCl}_{4}\right)$-Enhanced Precatalyst Preparation Stabilization and Initiation (EPPSI) Nano Molecules for Cancer Treatment and Cellular Therapeutics", J. Cancer Research and Therapeutic Interventions, Volume 1, Issue 1, Pages 01-10, 2018.

[291] R. Gobato, M. R. R. Gobato, A. Heidari, A. Mitra, "Spectroscopy and Dipole Moment of the Molecule $\mathrm{C}_{13} \mathrm{H}_{20} \mathrm{BeLi}_{2} \mathrm{SeSi}$ via Quantum Chemistry Using Ab Initio, Hartree-Fock Method in the Base Set CC-pVTZ and 6$311 G^{* *}(3 d f, 3 p d) "$, Arc Org Inorg Chem Sci 3 (5), Pages 402409, 2018. 
[292] A. Heidari, " $\mathrm{C}_{60}$ and $\mathrm{C}_{70}$-Encapsulating Carbon Nanotubes Incorporation into the Nano Polymeric Matrix (NPM) by Immersion of the Nano Polymeric Modified Electrode (NPME) as Molecular Enzymes and Drug Targets for Human Cancer Cells, Tissues and Tumors Treatment under Synchrotron and Synchrocyclotron Radiations", Integr Mol Med, Volume 5 (3): 1-8, 2018

[293] A. Heidari, "Two-Dimensional (2D) ${ }^{1} \mathrm{H}$ or Proton NMR, ${ }^{13} \mathrm{C}$ NMR, ${ }^{15} \mathrm{~N}$ NMR and ${ }^{31} \mathrm{P}$ NMR Spectroscopy Comparative Study on Malignant and Benign Human Cancer Cells and Tissues under Synchrotron Radiation with the Passage of Time", Glob Imaging Insights, Volume 3 (6): 1-8, 2018.

[294] A. Heidari, "FT-Raman Spectroscopy, Coherent Anti-Stokes Raman Spectroscopy (CARS) and Raman Optical Activity Spectroscopy (ROAS) Comparative Study on Malignant and Benign Human Cancer Cells and Tissues with the Passage of Time under Synchrotron Radiation", Glob Imaging Insights, Volume 3 (6): 1-8, 2018.

[295] A. Heidari, "A Modern and Comprehensive Investigation of Inelastic Electron Tunneling Spectroscopy (IETS) and Scanning Tunneling Spectroscopy on Malignant and Benign Human Cancer Cells, Tissues and Tumors through Optimizing Synchrotron Microbeam Radiotherapy for Human Cancer Treatments and Diagnostics: An Experimental Biospectroscopic Comparative Study", Glob Imaging Insights, Volume 3 (6): 1-8, 2018.

[296] A. Heidari, "A Hypertension Approach to Thermal Infrared Spectroscopy and Photothermal Infrared Spectroscopy Comparative Study on Malignant and Benign Human Cancer Cells and Tissues under Synchrotron Radiation with the Passage of Time", Glob Imaging Insights, Volume 3 (6): 1-8, 2018.

[297] A. Heidari, "Incredible Natural-Abundance Double-Quantum Transfer Experiment (INADEQUATE), Nuclear Overhauser Effect Spectroscopy (NOESY) and Rotating Frame Nuclear Overhauser Effect Spectroscopy (ROESY) Comparative Study on Malignant and Benign Human Cancer Cells and Tissues under Synchrotron Radiation", Glob Imaging Insights, Volume 3 (6): 1-8, 2018.

[298] A. Heidari, "2-Amino-9-((1S, 3R, 4R)-4-Hydroxy-3(Hydroxymethyl)-2-Methylenecyclopentyl)-1H-Purin6(9H)-One, 2-Amino-9-((1R, 3R, 4R)-4-Hydroxy-3(Hydroxymethyl)-2-Methylenecyclopentyl)-1H-Purin6(9H)-One, 2-Amino-9-((1R, 3R, 4S)-4-Hydroxy-3(Hydroxymethyl)-2-Methylenecyclopentyl)-1H-Purin6(9H)-One and 2-Amino-9-((1S, 3R, 4S)-4-Hydroxy-3(Hydroxymethyl)-2-Methylenecyclopentyl)-1H-Purin6(9H)-One-Enhanced Precatalyst Preparation Stabilization and Initiation Nano Molecules", Glob Imaging Insights, Volume 3 (6): 1-9, 2018.

[299] R. Gobato, M. R. R. Gobato, A. Heidari, A. Mitra, "Spectroscopy and Dipole Moment of the Molecule $\mathrm{C}_{13} \mathrm{H}_{20} \mathrm{BeLi}_{2} \mathrm{SeSi}$ via Quantum Chemistry Using $\mathrm{Ab}$ Initio, Hartree-Fock Method in the Base Set CC-pVTZ and 6$311 \mathrm{G}^{* *}(3 \mathrm{df}, 3 \mathrm{pd})$ ", American Journal of Quantum Chemistry and Molecular Spectroscopy, Vol. 2, No. 1, pp. 9-17, 2018

[300] A. Heidari, "Production of Electrochemiluminescence (ECL) Biosensor Using Os-Pd/HfC Nanocomposites for Detecting and Tracking of Human Gastroenterological Cancer Cells, Tissues and Tumors", Int J Med Nano Res 5: 1, 022-034, 2018.

[301] A. Heidari, "Enhancing the Raman Scattering for Diagnosis and Treatment of Human Cancer Cells, Tissues and Tumors Using Cadmium Oxide (CdO) Nanoparticles", J Toxicol Risk Assess 4: 1, 012-025, 2018.

[302] A. Heidari, "Human Malignant and Benign Human Cancer Cells and Tissues Biospectroscopic Analysis under Synchrotron Radiation Using Anti-Cancer Nano Drugs Delivery", Integr Mol Med, Volume 5 (5): 1-13, 2018.
[303] A. Heidari, "Analogous Nano Compounds of the Form $\mathrm{M}\left(\mathrm{C}_{8} \mathrm{H}_{8}\right)_{2}$ Exist for $\mathrm{M}=(\mathrm{Nd}, \mathrm{Tb}, \mathrm{Pu}, \mathrm{Pa}, \mathrm{Np}$, Th, and $\mathrm{Yb})-$ Enhanced Precatalyst Preparation Stabilization and Initiation (EPPSI) Nano Molecules", Integr Mol Med, Volume 5 (5): 18, 2018.

[304] A. Heidari, "Hadron Spectroscopy, Baryon Spectroscopy and Meson Spectroscopy Comparative Study on Malignant and Benign Human Cancer Cells and Tissues under Synchrotron Radiation”, Integr Mol Med, Volume 5 (5): 1-8, 2018.

[305] R. Gobato, M. R. R. Gobato, A. Heidari, "Raman Spectroscopy Study of the Nano Molecule $\mathrm{C}_{13} \mathrm{H}_{20} \mathrm{BeLi}_{2} \mathrm{SeSi}$ Using ab initio and Hartree-Fock Methods in the Basis Set CC-pVTZ and 6-311G** (3df, 3pd)", International Journal of Advanced Engineering and Science, Volume 7, Number 1, Pages 14-35, 2019.

[306] A. Heidari, R. Gobato, "Evaluating the Effect of Anti-Cancer Nano Drugs Dosage and Reduced Leukemia and Polycythemia Vera Levels on Trend of the Human Blood and Bone Marrow Cancers under Synchrotron Radiation", Trends in Res, Volume 2 (1): 1-8, 2019.

[307] A. Heidari, R. Gobato, "Assessing the Variety of Synchrotron, Synchrocyclotron and LASER Radiations and Their Roles and Applications in Human Cancer Cells, Tissues and Tumors Diagnosis and Treatment", Trends in Res, Volume 2 (1): 1-8, 2019.

[308] A. Heidari, R. Gobato, "Pros and Cons Controversy on Malignant Human Cancer Cells, Tissues and Tumors Transformation Process to Benign Human Cancer Cells, Tissues and Tumors", Trends in Res, Volume 2 (1): 1-8, 2019.

[309] A. Heidari, R. Gobato, "Three-Dimensional (3D) Simulations of Human Cancer Cells, Tissues and Tumors for Using in Human Cancer Cells, Tissues and Tumors Diagnosis and Treatment as a Powerful Tool in Human Cancer Cells, Tissues and Tumors Research and Anti-Cancer Nano Drugs Sensitivity and Delivery Area Discovery and Evaluation", Trends in Res, Volume 2 (1): 1-8, 2019.

[310] A. Heidari, R. Gobato, "Investigation of Energy Production by Synchrotron, Synchrocyclotron and LASER Radiations in Human Cancer Cells, Tissues and Tumors and Evaluation of Their Effective on Human Cancer Cells, Tissues and Tumors Treatment Trend", Trends in Res, Volume 2 (1): 1-8, 2019.

[311] A. Heidari, R. Gobato, "High-Resolution Mapping of DNA/RNA Hypermethylation and Hypomethylation Process in Human Cancer Cells, Tissues and Tumors under Synchrotron Radiation", Trends in Res, Volume 2 (2): 1-9, 2019.

[312] A. Heidari, "A Novel and Comprehensive Study on Manufacturing and Fabrication Nanoparticles Methods and Techniques for Processing Cadmium Oxide (CdO) Nanoparticles Colloidal Solution", Glob Imaging Insights, Volume 4 (1): 1-8, 2019.

[313] A. Heidari, "A Combined Experimental and Computational Study on the Catalytic Effect of Aluminum Nitride Nanocrystal (AIN) on the Polymerization of Benzene, Naphthalene, Anthracene, Phenanthrene, Chrysene and Tetracene", Glob Imaging Insights, Volume 4 (1): 1-8, 2019.

[314] A. Heidari, "Novel Experimental and Three-Dimensional (3D) Multiphysics Computational Framework of MichaelisMenten Kinetics for Catalyst Processes Innovation, Characterization and Carrier Applications", Glob Imaging Insights, Volume 4 (1): 1-8, 2019.

[315] A. Heidari, "The Hydrolysis Constants of Copper (I) $\left(\mathrm{Cu}^{+}\right)$and Copper (II) $\left(\mathrm{Cu}^{2+}\right)$ in Aqueous Solution as a Function of $\mathrm{pH}$ Using a Combination of $\mathrm{pH}$ Measurement and Biospectroscopic Methods and Techniques", Glob Imaging Insights, Volume 4 (1): 1-8, 2019.

[316] A. Heidari, "Vibrational Biospectroscopic Study of Ginormous Virus-Sized Macromolecule and Polypeptide Macromolecule as Mega Macromolecules Using Attenuated Total 
Reflectance-Fourier Transform Infrared (ATR-FTIR) Spectroscopy and Mathematica 11.3", Glob Imaging Insights, Volume 4 (1): 1-8, 2019.

[317] A. Heidari, "Three-Dimensional (3D) Imaging Spectroscopy of Carcinoma, Sarcoma, Leukemia, Lymphoma, Multiple Myeloma, Melanoma, Brain and Spinal Cord Tumors, Germ Cell Tumors, Neuroendocrine Tumors and Carcinoid Tumors under Synchrotron Radiation", Glob Imaging Insights, Volume 4 (1): 1-9, 2019.

[318] R. Gobato, M. R. R. Gobato, A. Heidari, "Storm Vortex in the Center of Paraná State on June 6, 2017: A Case Study", Sumerianz Journal of Scientific Research, Vol. 2, No. 2, Pages 24-31, 2019

[319] R. Gobato, M. R. R. Gobato, A. Heidari, "Attenuated Total Reflection-Fourier Transform Infrared (ATR-FTIR) Spectroscopy Study of the Nano Molecule $\mathrm{C}_{13} \mathrm{H}_{20} \mathrm{BeLi}_{2} \mathrm{SeSi}$ Using ab initio and Hartree-Fock Methods in the Basis Set RHF/CC-pVTZ and RHF/6-311G** (3df, 3pd): An Experimental Challenge to Chemists", Chemistry Reports, Vol. 2, No. 1, Pages 1-26, 2019

[320] A. Heidari, "Three-Dimensional (3D) Imaging Spectroscopy of Carcinoma, Sarcoma, Leukemia, Lymphoma, Multiple Myeloma, Melanoma, Brain and Spinal Cord Tumors, Germ Cell Tumors, Neuroendocrine Tumors and Carcinoid Tumors under Synchrocyclotron Radiation", Res Adv Biomed Sci Technol 1 (1): 01-17, 2019.

[321] R. Gobato, M. R. R. Gobato, A. Heidari, A. Mitra, "New Nano-Molecule Kurumi- $\mathrm{C}_{13} \mathrm{H}_{20} \mathrm{BeLi}_{2} \mathrm{SeSi} / \mathrm{C}_{13} \mathrm{H}_{19} \mathrm{BeLi} \mathrm{i}_{2} \mathrm{SeSi}$, and Raman Spectroscopy Using ab initio, Hartree-Fock Method in the Base Set CC-pVTZ and 6-311G** (3df, 3pd)", J Anal Pharm Res. 8 (1): 1-6, 2019.

[322] A. Heidari, J. Esposito, A. Caissutti, "The Importance of Attenuated Total Reflectance Fourier Transform Infrared (ATR-FTIR) and Raman Biospectroscopy of Single-Walled Carbon Nanotubes (SWCNT) and Multi-Walled Carbon Nanotubes (MWCNT) in Interpreting Infrared and Raman Spectra of Human Cancer Cells, Tissues and Tumors", Oncogen 2 (2): 1-21, 2019.

[323] A. Heidari, "Mechanism of Action and Their Side Effects at a Glance Prevention, Treatment and Management of Immune System and Human Cancer Nano Chemotherapy", Nanosci Technol 6 (1): 1-4, 2019.

[324] A. Heidari, J. Esposito, A. Caissutti, "The Quantum Entanglement Dynamics Induced by Non-Linear Interaction between a Moving Nano Molecule and a Two-Mode Field with Two-Photon Transitions Using Reduced Von Neumann Entropy and Jaynes-Cummings Model for Human Cancer Cells, Tissues and Tumors Diagnosis", Int J Crit Care Emerg Med 5 (2): 071-084, 2019.

[325] A. Heidari, J. Esposito, A. Caissutti, "Palytoxin TimeResolved Absorption and Resonance FT-IR and Raman Biospectroscopy and Density Functional Theory (DFT) Investigation of Vibronic-Mode Coupling Structure in Vibrational Spectra Analysis", J Pharm Drug Res, 3 (1): 150170, 2019.

[326] A. Heidari, J. Esposito, A. Caissutti, "Aplysiatoxin TimeResolved Absorption and Resonance FT-IR and Raman Biospectroscopy and Density Functional Theory (DFT) Investigation of Vibronic-Mode Coupling Structure in Vibrational Spectra Analysis", J Chem Sci Eng, 2 (2): 70-89, 2019.

[327] R. Gobato, M. R. R. Gobato, A. Heidari, A. Mitra, "Spectroscopy and Dipole Moment of the Molecule $\mathrm{C}_{13} \mathrm{H}_{20} \mathrm{BeLi}_{2} \mathrm{SeSi}$ via Quantum Chemistry Using $\mathrm{Ab}$ initio, Hartree-Fock Method in the Base Set CC-pVTZ and 6$311 \mathrm{G}^{* *}$ (3df, 3pd)", American Journal of Quantum Chemistry and Molecular Spectroscopy, 2 (1): 9-17, 2018.

[328] A. Heidari, J. Esposito, A. Caissutti, "Cyanotoxin TimeResolved Absorption and Resonance FT-IR and Raman Biospectroscopy and Density Functional Theory (DFT)
Investigation of Vibronic-Mode Coupling Structure in Vibrational Spectra Analysis", Br J Med Health Res. 6 (04): 21-60, 2019.

[329] A. Heidari, "Potential and Theranostics Applications of Novel Anti-Cancer Nano Drugs Delivery Systems in Preparing for Clinical Trials of Synchrotron Microbeam Radiation Therapy (SMRT) and Synchrotron Stereotactic Radiotherapy (SSRT) for Treatment of Human Cancer Cells, Tissues and Tumors Using Image Guided Synchrotron Radiotherapy (IGSR)", Ann Nanosci Nanotechnol. 3 (1): 1006-1019, 2019.

[330] A. Heidari, J. Esposito, A. Caissutti, "Study of Anti-Cancer Properties of Thin Layers of Cadmium Oxide (CdO) Nanostructure", Int J Analyt Bioanalyt Methods 1 (1): 003 022, 2019.

[331] A. Heidari, J. Esposito, A. Caissutti, "Alpha-Conotoxin, Omega-Conotoxin and Mu-Conotoxin Time-Resolved Absorption and Resonance FT-IR and Raman Biospectroscopy and Density Functional Theory (DFT) Investigation of Vibronic-Mode Coupling Structure in Vibrational Spectra Analysis", International Journal of Advanced Chemistry, 7 (1) 52-66, 2019.

[332] A. Heidari, "Clinical and Medical Pros and Cons of Human Cancer Cells' Enzymotherapy, Immunotherapy, Chemotherapy, Radiotherapy, Hormone Therapy and Targeted Therapy Process under Synchrotron Radiation: A Case Study on Mechanism of Action and Their Side Effects", Parana Journal of Science and Education (PJSE)-v. 5, n. 3, (1-23) May 2, 2019.

[333] A. Heidari, "The Importance of the Power in CMOS Inverter Circuit of Synchrotron and Synchrocyclotron Radiations Using $50(\mathrm{~nm})$ and $100(\mathrm{~nm})$ Technologies and Reducing the Voltage of Power Supply", Radiother Oncol Int. 1 (1): 1002 1015, 2019.

[334] A. Heidari, J. Esposito, A. Caissutti, "The Importance of Quantum Hydrodynamics (QHD) Approach to Single-Walled Carbon Nanotubes (SWCNT) and Multi-Walled Carbon Nanotubes (MWCNT) in Genetic Science", SCIOL Genet Sci. 2 (1): 113-129, 2019.

[335] A. Heidari, J. Esposito, A. Caissutti, "Anatoxin-a and Anatoxin-a(s) Time-Resolved Absorption and Resonance FT-IR and Raman Biospectroscopy and Density Functional Theory (DFT) Investigation of Vibronic-Mode Coupling Structure in Vibrational Spectra Analysis", Saudi J Biomed Res, 4 (4): 174-194, 2019.

[336] R. Gobato, M. R. R. Gobato, A. Heidari, "Evidence of Tornado Storm Hit the Counties of Rio Branco do Ivaí and Rosario de Ivaí, Southern Brazil", Sci Lett, 7 (1): 32-40, 2019.

[337] M. Jeyaraj, V. Mahalingam, A. Indhuleka, P. Sennu, M. S. Ho, A. Heidari, "Chemical Analysis of Surface Water Quality of River Noyyal Connected Tank in Tirupur District, Tamil Nadu, India", Water and Energy International, Volume 62r, Issue 1, pp. 63-68, 2019.

[338] A. Heidari, J. Esposito, A. Caissutti, "6-Methoxy-8-[[6Methoxy-8-[[6-Methoxy-2-Methyl-1-(2-Methylpropyl)-3,4Dihydro-1H-Isoquinolin-7-yl]Oxy]-2-Methyl-1-(2-

Methylpropyl)-3,4-Dihydro-1H-Isoquinolin-7-yl]Oxy]-2Methyl-1-(2-Methylpropyl)-3,4-Dihydro-1H-Isoquinolin-7ol Time-Resolved Absorption and Resonance FT-IR and Raman Biospectroscopy and Density Functional Theory (DFT) Investigation of Vibronic-Mode Coupling Structure in Vibrational Spectra Analysis", J. Adv. Phys. Chem., Volume 1, Issue 1, pp. 1-6, 2019.

[339] A. Heidari, J. Esposito, A. Caissutti, "Shiga Toxin and ShigaLike Toxin (SLT) Time-Resolved Absorption and Resonance FT-IR and Raman Biospectroscopy and Density Functional Theory (DFT) Investigation of Vibronic-Mode Coupling Structure in Vibrational Spectra Analysis", Annal Biostat \& Biomed Appli. 2 (3): 1-4, 2019.

[340] A. Heidari, J. Esposito, A. Caissutti, "Alpha-Bungarotoxin, 
Beta-Bungarotoxin and Kappa-Bungarotoxin TimeResolved Absorption and Resonance FT-IR and Raman Biospectroscopy and Density Functional Theory (DFT) Investigation of Vibronic-Mode Coupling Structure in Vibrational Spectra Analysis", Archives of Pharmacology and Pharmaceutical Sciences, ReDelve, Volume 2019, Issue 01, pp. 1-24, 2019.

[341] A. Heidari, J. Esposito, A. Caissutti, "Okadaic Acid TimeResolved Absorption and Resonance FT-IR and Raman Biospectroscopy and Density Functional Theory (DFT) Investigation of Vibronic-Mode Coupling Structure in Vibrational Spectra Analysis", Int J Analyt Bioanalyt Methods 1 (1): 1-19, 2019.

[342] A. Heidari, "Investigation of the Processes of Absorption, Distribution, Metabolism and Elimination (ADME) as Vital and Important Factors for Modulating Drug Action and Toxicity", Open Access J Oncol, 2 (1): 180010-180012, 2019.

[343] A. Heidari, J. Esposito, A. Caissutti, "Pertussis Toxin TimeResolved Absorption and Resonance FT-IR and Raman Biospectroscopy and Density Functional Theory (DFT) Investigation of Vibronic-Mode Coupling Structure in Vibrational Spectra Analysis", Chemistry Reports, Vol. 1 Iss. 2, Pages 1-5, 2019

[344] R. Gobato, M. R. R. Gobato, A. Heidari, "Rhodochrosite as Crystal Oscillator", Am J Biomed Sci \& Res. 3 (2), 187, 2019.

[345] A. Heidari, J. Esposito, A. Caissutti, "Tetrodotoxin (TTX) Time-Resolved Absorption and Resonance FT-IR and Raman Biospectroscopy and Density Functional Theory (DFT) Investigation of Vibronic-Mode Coupling Structure in Vibrational Spectra Analysis", Journal of New Developments in Chemistry, Volume No: 2, Issue No: 3, Page Numbers 2648, 2019

[346] A. Heidari, J. Esposito, A. Caissutti, "The Importance of Analysis of Vibronic-Mode Coupling Structure in Vibrational Spectra of Supramolecular Aggregates of $\left(C A^{*} M\right)$ Cyanuric Acid (CA) and Melamine (M) beyond the Franck-Condon Approximation", Journal of Clinical and Medical Images, 2 (2): 1-20, 2019.

[347] A. Heidari, J. Esposito, A. Caissutti, "Microcystin-LR TimeResolved Absorption and Resonance FT-IR and Raman Biospectroscopy and Density Functional Theory (DFT) Investigation of Vibronic-Mode Coupling Structure in Vibrational Spectra Analysis", Malaysian Journal of Chemistry, Vol. 21 (1), 70-95, 2019.

[348] A. Heidari, J. Esposito, A. Caissutti, "Botulinum Toxin TimeResolved Absorption and Resonance FT-IR and Raman Biospectroscopy and Density Functional Theory (DFT) Investigation of Vibronic-Mode Coupling Structure in Vibrational Spectra Analysis", Journal of Mechanical Design and Vibration, vol. 7, no. 1: 1-15, 2019.

[349] A. Heidari, J. Esposito, A. Caissutti, "Domoic Acid (DA) Time-Resolved Absorption and Resonance FT-IR and Raman Biospectroscopy and Density Functional Theory (DFT) Investigation of Vibronic-Mode Coupling Structure in Vibrational Spectra Analysis", Cientific Clinical Oncology Journal 1. 2: 03-07, 2019.

[350] A. Heidari, J. Esposito, A. Caissutti, "Surugatoxin (SGTX) Time-Resolved Absorption and Resonance FT-IR and Raman Biospectroscopy and Density Functional Theory (DFT) Investigation of Vibronic-Mode Coupling Structure in Vibrational Spectra Analysis", Cientific Clinical Oncology Journal 1. 2: 14-18, 2019.

[351] A. Heidari, J. Esposito, A. Caissutti, "Decarbamoylsaxitoxin Time-Resolved Absorption and Resonance FT-IR and Raman Biospectroscopy and Density Functional Theory (DFT) Investigation of Vibronic-Mode Coupling Structure in Vibrational Spectra Analysis", Cientific Clinical Oncology Journal 1. 2: 19-23, 2019.

[352] A. Heidari, J. Esposito, A. Caissutti, "Gonyautoxin (GTX) Time-Resolved Absorption and Resonance FT-IR and
Raman Biospectroscopy and Density Functional Theory (DFT) Investigation of Vibronic-Mode Coupling Structure in Vibrational Spectra Analysis", Cientific Clinical Oncology Journal 1. 2: 24-28, 2019

[353] A. Heidari, J. Esposito, A. Caissutti, "Hislrionicotoxin TimeResolved Absorption and Resonance FT-IR and Raman Biospectroscopy and Density Functional Theory (DFT) Investigation of Vibronic-Mode Coupling Structure in Vibrational Spectra Analysis", Cientific Drug Delivery Research 1. 1: 01-06, 2019.

[354] A. Heidari, J. Esposito, A. Caissutti, "Dihydrokainic Acid Time-Resolved Absorption and Resonance FT-IR and Raman Biospectroscopy and Density Functional Theory (DFT) Investigation of Vibronic-Mode Coupling Structure in Vibrational Spectra Analysis", Cientific Drug Delivery Research 1. 1: 07-12, 2019.

[355] A. Heidari, J. Esposito, A. Caissutti, "Aflatoxin B1 (AFB1), B2 (AFB2), G1 (AFG1), G2 (AFG2), M1 (AFM1), M2 (AFM2), Q1 (AFQ1) and P1 (AFP1) Time-Resolved Absorption and Resonance FT-IR and Raman Biospectroscopy and Density Functional Theory (DFT) Investigation of Vibronic-Mode Coupling Structure in Vibrational Spectra Analysis", Cientific Drug Delivery Research 1. 1: 25-32, 2019.

[356] A. Heidari, J. Esposito, A. Caissutti, "Mycotoxin TimeResolved Absorption and Resonance FT-IR and Raman Biospectroscopy and Density Functional Theory (DFT) Investigation of Vibronic-Mode Coupling Structure in Vibrational Spectra Analysis", Cientific Drug Delivery Research 1. 1: 13-18, 2019.

[357] A. Heidari, J. Esposito, A. Caissutti, "Bufotoxin TimeResolved Absorption and Resonance FT-IR and Raman Biospectroscopy and Density Functional Theory (DFT) Investigation of Vibronic-Mode Coupling Structure in Vibrational Spectra Analysis", Cientific Drug Delivery Research 1. 1: 19-24, 2019.

[358] A. Heidari, J. Esposito, A. Caissutti, "Kainic Acid (Kainite) Time-Resolved Absorption and Resonance FT-IR and Raman Biospectroscopy and Density Functional Theory (DFT) Investigation of Vibronic-Mode Coupling Structure in Vibrational Spectra Analysis", Cientific Journal of Neurology 1. 2: $02-07,2019$.

[359] A. Heidari, J. Esposito, A. Caissutti, "Nereistoxin TimeResolved Absorption and Resonance FT-IR and Raman Biospectroscopy and Density Functional Theory (DFT) Investigation of Vibronic-Mode Coupling Structure in Vibrational Spectra Analysis", Cientific Journal of Neurology 1. 2: 19-24, 2019.

[360] A. Heidari, J. Esposito, A. Caissutti, "Spider Toxin and Raventoxin Time-Resolved Absorption and Resonance FTIR and Raman Biospectroscopy and Density Functional Theory (DFT) Investigation of Vibronic-Mode Coupling Structure in Vibrational Spectra Analysis", Parana Journal of Science and Education. Vol. 5, No. 4, pp. 1-28, 2019.

[361] A. Heidari, J. Esposito, A. Caissutti, "Ochratoxin A Ochratoxin B, Ochratoxin C, Ochratoxin $\alpha$ and Ochratoxin TA Time-Resolved Absorption and Resonance FT-IR and Raman Biospectroscopy and Density Functional Theory (DFT) Investigation of Vibronic-Mode Coupling Structure in Vibrational Spectra Analysis", Cientific Drug Delivery Research 1. 2: 03-10, 2019.

[362] A. Heidari, J. Esposito, A. Caissutti, "Brevetoxin A and B Time-Resolved Absorption and Resonance FT-IR and Raman Biospectroscopy and Density Functional Theory (DFT) Investigation of Vibronic-Mode Coupling Structure in Vibrational Spectra Analysis", Cientific Drug Delivery Research 1. 2: 11-16, 2019.

[363] A. Heidari, J. Esposito, A. Caissutti, "Lyngbyatoxin-a TimeResolved Absorption and Resonance FT-IR and Raman Biospectroscopy and Density Functional Theory (DFT) Investigation of Vibronic-Mode Coupling Structure in 
Vibrational Spectra Analysis", Cientific Drug Delivery Research 1. 2: 23-28, 2019.

[364] A. Heidari, J. Esposito, A. Caissutti, "Balraechotoxin (BTX) Time-Resolved Absorption and Resonance FT-IR and Raman Biospectroscopy and Density Functional Theory (DFT) Investigation of Vibronic-Mode Coupling Structure in Vibrational Spectra Analysis", Cientific Journal of Neurology 1. 3: 01-05, 2019.

[365] A. Heidari, J. Esposito, A. Caissutti, "Hanatoxin TimeResolved Absorption and Resonance FT-IR and Raman Biospectroscopy and Density Functional Theory (DFT) Investigation of Vibronic-Mode Coupling Structure in Vibrational Spectra Analysis", Int. J. Pharm. Sci. Rev. Res., 57 (1), Pages: 21-32, 2019.

[366] A. Heidari, J. Esposito, A. Caissutti, "Neurotoxin and AlphaNeurotoxin Time-Resolved Absorption and Resonance FTIR and Raman Biospectroscopy and Density Functional Theory (DFT) Investigation of Vibronic-Mode Coupling Structure in Vibrational Spectra Analysis", J Biomed Sci \& Res. 3 (6), 550-563, 2019.

[367] A. Heidari, J. Esposito, A. Caissutti, "Antillatoxin (ATX) TimeResolved Absorption and Resonance FT-IR and Raman Biospectroscopy and Density Functional Theory (DFT) Investigation of Vibronic-Mode Coupling Structure", American Journal of Optics and Photonics. Vol. 7, No. 1, pp. 18-27, 2019.

[368] R. Gobato, M. R. R. Gobato, A. Heidari, "Calculation by UFF Method of Frequencies and Vibrational Temperatures of the Unit Cell of the Rhodochrosite Crystal", International Journal of Advanced Chemistry, 7 (2) 77-81, 2019.

[369] A. Heidari, J. Esposito, A. Caissutti, "Analysis of VibronicMode Coupling Structure in Vibrational Spectra of Fuzeon as a 36 Amino Acid Peptide for HIV Therapy beyond the MultiDimensional Franck-Condon Integrals Approximation", International Journal of Advanced Chemistry, 7 (2) 82-96, 2019.

[370] A. Heidari, J. Esposito, A. Caissutti, "Debromoaplysiatoxin Time-Resolved Absorption and Resonance FT-IR and Raman Biospectroscopy and Density Functional Theory (DFT) Investigation of Vibronic-Mode Coupling Structure in Vibrational Spectra Analysis", Applied Chemistry, 2 (1) 1754, 2019.

[371] A. Heidari, J. Esposito, A. Caissutti, "Enterotoxin TimeResolved Absorption and Resonance FT-IR and Raman Biospectroscopy and Density Functional Theory (DFT) Investigation of Vibronic-Mode Coupling Structure in Vibrational Spectra Analysis", JRL J Sci Technol. vol1-iss2: jst1001, 1-16, 2019.

[372] R. Gobato, M. R. R. Gobato, A. Heidari, A. Mitra, "Rhodochrosite Optical Indicatrix", Peer Res Nest. 1 (3) 1-2, 2019.

[373] A. Heidari, J. Esposito, A. Caissutti, "Anthrax Toxin TimeResolved Absorption and Resonance FT-IR and Raman Biospectroscopy and Density Functional Theory (DFT) Investigation of Vibronic-Mode Coupling Structure in Vibrational Spectra Analysis", Research \& Reviews: Journal of Computational Biology. 8 (2): 23-51, 2019.

[374] A. Heidari, J. Esposito, A. Caissutti, "Kalkitoxin TimeResolved Absorption and Resonance FT-IR and Raman Biospectroscopy and Density Functional Theory (DFT) Investigation of Vibronic-Mode Coupling Structure in Vibrational Spectra Analysis", Can J Biomed Res \& Tech. 2 (1): 1-21, 2019.

[375] A. Heidari, J. Esposito, A. Caissutti, "Neosaxitoxin TimeResolved Absorption and Resonance FT-IR and Raman Biospectroscopy and Density Functional Theory (DFT) Investigation of Vibronic-Mode Coupling Structure in Vibrational Spectra Analysis", Clin Case Studie Rep, Volume 2 (3): 1-14, 2019.
[376] A. Heidari, J. Esposito, A. Caissutti, "6-Methoxy-8-[[6Methoxy-8-[[6- Methoxy-2-Methyl-1-(2-Methylpropyl)3,4-Dihydro-1H-Isoquinolin-7-yl]Oxy]-2- Methyl-1-(2Methylpropyl)-3,4-Dihydro-1H-Isoquinolin-7-yl]Oxy]-2Methyl-1-(2- Methylpropyl)-3,4-Dihydro-1H-Isoquinolin-7ol Time-Resolved Absorption and Resonance FT-IR and Raman Biospectroscopy and Density Functional Theory (DFT) Investigation of Vibronic-Mode Coupling Structure in Vibrational Spectra Analysis", Clin Case Studie Rep, Volume 2 (3): 1-14, 2019.

[377] A. Heidari, "Comparison of Synchrotron Radiation and Synchrocyclotron Radiation Performance in Monitoring of Human Cancer Cells, Tissues and Tumors", Clin Case Studie Rep, Volume 2 (3): 1-12, 2019.

[378] A. Heidari, J. Esposito, A. Caissutti, "Kalkitoxin TimeResolved Absorption and Resonance FT-IR and Raman Biospectroscopy and Density Functional Theory (DFT) Investigation of Vibronic-Mode Coupling Structure in Vibrational Spectra Analysis", Clin Case Studie Rep, Volume 2 (3): 1-14, 2019.

[379] A. Heidari, J. Esposito, A. Caissutti, "Diphtheria Toxin TimeResolved Absorption and Resonance FT-IR and Raman Biospectroscopy and Density Functional Theory (DFT) Investigation of Vibronic-Mode Coupling Structure in Vibrational Spectra Analysis: A Spectroscopic Study on an Anti-Cancer Drug", Clin Case Studie Rep, Volume 2 (3): 114, 2019.

[380] A. Heidari, J. Esposito, A. Caissutti, "Symbiodinolide TimeResolved Absorption and Resonance FT-IR and Raman Biospectroscopy and Density Functional Theory (DFT) Investigation of Vibronic-Mode Coupling Structure in Vibrational Spectra Analysis", Clin Case Studie Rep, Volume 2 (3): 1-14, 2019.

[381] A. Heidari, J. Esposito, A. Caissutti, "Saxitoxin TimeResolved Absorption and Resonance FT-IR and Raman Biospectroscopy and Density Functional Theory Investigation of Vibronic-Mode Coupling Structure in Vibrational Spectra Analysis", Am J Exp Clin Res. 6 (4): 364-377, 2019.

[382] A. Heidari, J. Esposito, A. Caissutti, "Saxitoxin TimeResolved Absorption and Resonance FT-IR and Raman Biospectroscopy and Density Functional Theory Investigation of Vibronic-Mode Coupling Structure in Vibrational Spectra Analysis", Am J Exp Clin Res. 6 (4): 364-377, 2019.

[383] R. Gobato, M. R. R. Gobato, A. Heidari, A. Mitra, "HartreeFock Methods Analysis Protonated Rhodochrosite Crystal and Potential in the Elimination of Cancer Cells through Synchrotron Radiation", Vol. 5, No. 3, pp. 27-36, 2019.

[384] R. Gobato, I. K. K. Dosh, A. Heidari, A. Mitra, M. R. R. Gobato, "Perspectives on the Elimination of Cancer Cells Using Rhodochrosite Crystal Through Synchrotron Radiation, and Absorption the Tumoral and Non-Tumoral Tissues", Arch Biomed Eng \& Biotechnol. 3 (2): 1-2, 2019.

[385] R. Gobato, M. R. R. Gobato, A. Heidari, A. Mitra, "Unrestricted Hartree-Fock Computational Simulation in a Protonated Rhodochrosite Crystal", Phys Astron Int J. 3 (6):220-228, 2019.

[386] A. Heidari, K. Schmitt, M. Henderson, E. Besana, "Perspectives on Sub- Nanometer Level of Electronic Structure of the Synchrotron with Mendelevium Nanoparticles for Elimination of Human Cancer Cells, Tissues and Tumors Treatment Using Mathematica 12.0", Journal of Energy Conservation, Volume 1, Issue 2, Pages 46-73, 2019.

[387] A. Heidari, K. Schmitt, M. Henderson, E. Besana, "Simulation of Interaction of Synchrotron Radiation Emission as a Function of the Beam Energy and Bohrium Nanoparticles Using 3D Finite Element Method (FEM) as an Optothermal Human Cancer Cells, Tissues and Tumors Treatment", Current Research in Biochemistry and Molecular Biology, 1 (1), 17-44, 2019. 
[388] A. Heidari, K. Schmitt, M. Henderson, E. Besana, "Investigation of Interaction between Synchrotron Radiation and Thulium Nanoparticles for Human Cancer Cells, Tissues and Tumors Treatment", European Journal of Scientific Exploration, Volume 2, Issue 3, Pages 1-8, 2019.

Received on 05-11-2019

Accepted on 26-11-2019

Published on 29-11-2019

https://doi.org/10.30683/1927-7229.2019.08.07

(C) 2019 Heidari et al.; Licensee Neoplasia Research.

This is an open access article licensed under the terms of the Creative Commons Attribution Non-Commercial License (http://creativecommons.org/licenses/by-nc/3.0/) which permits unrestricted, non-commercial use, distribution and reproduction in any medium, provided the work is properly cited. 